\title{
Complexation of Lysozyme with Sodium Caseinate and Micellar Casein in
}

\section{Aqueous Buffered Solutions}

Yurij A. Antonov*

N.M.Emanuel Institute of Biochemical Physics, Russian Academy of Sciences, Kosigin Str. 4. 119334 Moscow, Russia

Paula Moldenaers

Soft Matter Rheology and Technology, Department of Chemical Engineering, KU Leuven, Celestijnenlaan 200f, Box 2424, B-3001 Leuven, Belgium

\section{Ruth Cardinaels}

Polymer Technology, Department of Mechanical Engineering, TU Eindhoven, Box 513, 5600MB Eindhoven, The Netherlands

Soft Matter Rheology and Technology, Department of Chemical Engineering, KU Leuven, Celestijnenlaan 200f, Box 2424, B-3001 Leuven, Belgium

Published in Food Hydrocolloids, 62, 102-118 (2017)

Original publication can be accessed at:

http://www.sciencedirect.com/science/article/pii/S0268005X16303009 


\title{
Complexation of Lysozyme with Sodium Caseinate and Micellar Casein in
} Aqueous Buffered Solutions

\author{
Yurij A. Antonov* \\ N.M.Emanuel Institute of Biochemical Physics, Russian Academy of Sciences, Kosigin Str. 4. \\ 119334 Moscow, Russia \\ Paula Moldenaers \\ Soft Matter Rheology and Technology, Department of Chemical Engineering, KU Leuven, \\ Celestijnenlaan 200f, Box 2424, B-3001 Leuven , Belgium \\ Ruth Cardinaels
}

Polymer Technology, Department of Mechanical Engineering, TU Eindhoven, Box 513, 5600MB Eindhoven, The Netherlands

Soft Matter Rheology and Technology, Department of Chemical Engineering, KU Leuven, Celestijnenlaan 200f, Box 2424, B-3001 Leuven, Belgium

\begin{abstract}
We present an extended structural and morphological study of the complexation of lysozyme (Lys) with sodium caseinate (SC) and micellar casein (MC) by means of turbidity measurements, phase analysis, dynamic, static and electrophoretic light scattering, bright-field and confocal laser scanning (CLSM) microscopy, fluorescence anisotropy and circular dichroism measurements. The solution behavior, structure, effective charge and morphology of the formed complexes as well as the protein structure within the complexes are dependent on the state of the casein molecules ( $\mathrm{SC}$ versus $\mathrm{MC}$ ), $\mathrm{pH}$, ionic strength, and the [Cat $\left.{ }^{+}\right] /\left[\mathrm{An}^{-}\right]$ charge ratio (ChR). Absorption measurements indicate complexation of Lys with caseins at a $\mathrm{pH}$ as high as 11.29 ( $I=0.01)$. At ChR>1, i.e. in excess of lysozyme, CLSM clearly showed formation of complex Lys/SC particles with a neutral core and an exterior part consisting exclusively of hydrophilic Lys macromolecules, whereas in the case of Lys/MC particles a uniform distribution of both proteins was observed. Binding of Lys with SC or MC leads to disruption of the secondary structure of Lys. Binding isotherms from fluorescence anisotropy are well described by an independent binding site model.
\end{abstract}

*Corresponding author: Yurij A. Antonov, e-mail:chehonter@yandex.ru

Key words: Lysozyme, caseins, protein complexes, structure, morphology

\section{INTRODUCTION}

Protein-protein interactions drive many biophysical processes of proteins in solution, such as aggregation, solubilisation and desolubilisation, and phase transitions including crystallization, 
gelation, and amorphous precipitation. Many of these processes are of significant research interest because of their practical importance. In the biopharmaceutical industry, it is crucial to prevent therapeutic proteins from aggregation during the manufacturing process and storage in order to maintain safety and efficacy (Schmidt, Havekost, Kaiser, Kauling, \&Henzler, 2005). In addition, protein crystallization and precipitation are used for industrialized recombinant protein purification processes (Gunton, Shiryayev, \& Pagan, 2007). Furthermore, studying protein-protein interactions could shed light on the mechanisms of protein condensation (or phase transition) diseases, such as cataract and sickle cell disease (Uversky \& Fink, 2006). Finally, protein-protein interactions may play an essential role in many human neurodegenerative diseases attributed to protein aggregation, such as Parkinson and Alzheimer diseases (Howel, 1992). Protein-protein interactions are also relevant for food and nutrition. They can affect the nutritional and organoleptic quality of food products during manufacture, storage and consumption. Many studies, to date, display interesting and technologically useful properties produced by protein interactions including enhanced gelation properties originating from synergistic interactions and new textural properties as a result of aggregation of oppositely charged proteins and phase separation (Howell, Sabila, Grootveld, \& Williams, 1996; Bouhallab \& Croguenneg, 2014). Clearly, knowledge of protein interactions can lead to a better understanding of biochemical changes in food products during processing and storage such as for example the aggregation of proteins in fish leading to toughening upon frozen storage (Howel,1996). Furthermore, an understanding of the effect of protein structure on protein-protein interactions, for example, of smooth and skeletal muscle proteins permits the manipulation of protein side chains in order to enhance gelation properties (Howell et al, 1996; Bouhallab et al., 2014). However, both experimental data and the corresponding understanding of how structural and conformational properties of the interacting proteins affect complex formation and the resulting morphology as well as the molecular and thermal aggregation properties of the proteins in complexes, is presently lacking for most proteins. Proteins might exhibit long-lasting interactions when being part of a protein complex or may be carrying another protein merely for a limited amount of time, for example to modify it. Depending on the type and strength of the interactions, which are also largely affected by the physico-chemical conditions of the medium, different supramolecular structures such as fibrils, spherical particles or aggregates can be formed (Winkler, Roland \& Cherstvy, 2014). Hence, understanding the driving forces that trigger protein self-assembly and the successive steps leading to the development of supramolecular structures is of paramount importance for controlling the shape, size and properties of these structures. Proteins bind to each other through a combination of coulomb and hydrophobic interactions, van der Waals forces, and salt bridges between specific binding domains on each protein (Winkler, et al., 2014). In general, the protein-protein interaction energy is only slightly higher than the thermal energy $k T$, enabling the proteins to rearrange locally with respect to each other allowing 
them to adopt their preferential orientations (Winkler, et al., 2014). Comparisons of the relaxation phenomena of protein-protein complexes with that of polyelectrolyte complexes have shown (Winkler, et al., 2014) that the main difference between protein molecules and polyelectrolytes is the distance between the opposite charges. The distance between opposite charges on different protein molecules is larger than for polyelectrolytes because optimal 3D packing is more complicated in proteins than in linear polyelectrolytes. It is therefore not surprising that when two proteins are different in size, it is difficult to obtain full charge neutralization (Desfougères, Croguennec, Lechevalier, Bouhallab, \& Nau, F., 2010). A variety of macromolecular complexes of globular proteins has recently been characterized (Desfougères, et al., 2010; Van der Linden \& Venema, 2007; Coers, Permyakov, Permyakov, Uversky, \& Fink, 2002; Krebs, et al., 2000; Sagis, Veerman, \& van der Linden, 2004; Krebs, Delvin,\& Donald, 2007).Linear and fibrillar assemblies, such as amyloid fibrils, are favored at $\mathrm{pHs}$ far from the isoelectric point (pI) and at low ionic strength when electrostatic repulsion is high. Contrarily, spherical objects are obtained by incubation of proteins at a $\mathrm{pH}$ close to their $\mathrm{pI}$ and at an ionic strength favoring electrostatic interaction (Desfougères, et al., 2010; Krebs et al, 2007). Although plenty of studies on complexation of globular proteins have been performed to characterize macromolecular protein complexes, few studies are available (Anema, \& de Kruif, 2013; Pan, Shaoyong, Yao, \& Shao, 2007) on interactions in systems containing unordered protein(s).

In this study we examine the association behavior in aqueous buffered solutions of two acid proteins (sodium caseinate and micellar casein), both with an intrinsically disordered structure, but having a different dispersion state (molecularly versus colloidally dispersed state) with a basic globular protein (lysozyme).The scope of the study is to elucidate the interaction and complexation of casein and lysozyme, including the structure and composition of the complex particles, the allocation of the proteins within the complex, as well as the solution properties and peculiarities of the morphology of the complex system. Therefore dynamic and static light scattering, confocal laser scanning microscopy (CLSM), optical microscopy, phase analysis, electrophoretic mobility, and absorption measurements are utilized.

Casein is a member of the group of secreted calcium (phosphate)-binding phosphoproteins. It is a major milk protein, which naturally occurs as micellar casein (MC), with each micelle containing around 20,000-150,000 casein molecules with $\alpha_{s 1}, \alpha_{s 2}, \beta$, and $\kappa$ caseins in the proportion 3:1:3:1 and $8 \%$ in mass of phosphate and calcium ions (Pitkowski, Durand, \& Nicolai, 2008; Holt, Carver, Ecroyd, and Thorn, 2013). Casein micelles are roughly spherical core-shell particles with outer diameters ranging from 50-500 $\mathrm{nm}$ and an average size of 120-150 nm (Dalgleish, Spagnuolo, \& Goff, 2004). The core is now generally described as a homogeneous web of caseins in which calcium phosphate nanoclusters are uniformly distributed (Horne, 2002; Marchin, Putaux, Pignon, \& Léonil, 2007). The shell is essentially made of $\kappa$-caseins that extend into the aqueous phase as a 
polyelectrolyte brush and in this way produce short-range repulsions between the micelles (Tuinier \& De Kruif, 2002). Sodium caseinate (SC) is derived from native micellar casein and forms small star-like associates in aqueous solution (Pitkowski et al., 2008). Lysozyme (Lys) is a well-studied 14.3 kDa globular protein with enzymatic activity that has a net positive charge in the $\mathrm{pH}$ range up to its $\mathrm{pI}(10.5)$.

At present, there is only limited knowledge about the effects of the dispersion state of casein (SC versus MC) on the segregative phase behavior of casein with other proteins (Polyakov, Grinberg, Antonov, \& Tolstoguzov,1979) or polysaccharides (Antonov, Lefebvre, \& Doublier, 2007). However, the associative phase behavior of casein with other proteins as a function of its dispersion state is unexplored. This limited knowledge combined with the potential applications of lysozymecasein systems provides a strong motivation to study and compare their complexation and solution behavior, the morphology of the complexes formed in Lys/SC and Lys/MC systems as a function of concentration, and $\mathrm{pH}$, as well as the structure of the proteins in the complexes, aiming at gaining additional insight in protein/protein interactions.

\section{EXPERIMENTAL SECTION}

\section{Materials.}

Proteins and reagents. Lys from chicken egg white (dialyzed, lyophilized powder) was purchased from Sigma-Aldrich and used without further purification. The SC sample (14.1\% protein nitrogen, 90\% protein, $5.5 \%$ water content, $3.8 \%$ ash, $0.02 \%$ calcium) was procured from Sigma-Aldrich. Its isoelectric point is around $\mathrm{pH}=4.7-5.2$ (Swaisgood, 1992). The weight average molecular mass of the SC sample in $0.15 \mathrm{M} \mathrm{NaCl}$ solutions is $320 \mathrm{kDa} \pm 20 \mathrm{kDa}$ (Antonov \& Moldenaers, 2009). $\beta$-casein was purchased from Sigma-Aldrich and used without further purification. The MC sample, supplied by Laboratoire de Recherche et de Technologie Laitière (P. Schuck, LRTL, INRA Rennes, France), was a native calcium phosphocaseinate sample purified by ultrafiltration and diafiltration and then freeze-dried (Bourriot, Garnier, Doublier, 1999; Schuck, Piot, Mejean, Legraet, Fauquant, Brule, \&

134 Maubois, J., 1994). It had the following characteristics: total protein content $90.7 \%$, protein nitrogen $14.21 \%$, non-casein protein $5.0 \%$, lactose $0.5 \%$, salts $8.3 \%$, calcium $2.7 \%$. All other reagents were of analytical reagent grade. Milli-Q ultrapure water was used in all experiments. Most experiments were performed in a dilute mono/bisphosphate $\left(\mathrm{KH}_{2} \mathrm{PO}_{4}+\mathrm{K}_{2} \mathrm{HPO}_{4}\right)$ buffer with $I=0.01$, where $\mathrm{I}$ is made dimensionless with $\mathrm{m}^{0}=1 \mathrm{~mol} / \mathrm{kg}$. 
140 casein with the required concentrations, the weighed amount of biopolymer sample was gradually 141 added to phosphate buffer $(\mathrm{pH} 7.0, I=0.01)$ at $23^{\circ} \mathrm{C}$ and stirred, first for $1 \mathrm{~h}$ at this temperature and

142 then for $1 \mathrm{~h}$ at $45^{\circ} \mathrm{C}$. Lys solutions were prepared by dispersing the protein in the buffer under stirring 143 for $1 \mathrm{~h}$ at $23^{\circ} \mathrm{C}$. The resulting solutions of SC, $\beta$-casein, and lys were centrifuged at 50,000g and $14423^{\circ} \mathrm{C}$ for $1 \mathrm{~h}$ to remove insoluble particles. Colloidal solutions of MC were prepared by dispersing 145 the protein in the buffer under stirring for $14 \mathrm{~h}$ at $23^{\circ} \mathrm{C}$ with subsequent centrifugation at $2000 \mathrm{~g}$ and $14623^{\circ} \mathrm{C}$ for $1 \mathrm{~h}$. The final solutions of MC were stable against aggregation for more than one month. 147 The lysozyme content in the stock solution was determined by means of UV absorption using the 148 extinction coefficient for highly purified lysozyme which is $2.64 \mathrm{ml} \mathrm{mg}^{-1} \mathrm{~cm}^{-1}$ at $281.5 \mathrm{~nm}$ in $0.1 \mathrm{M}$ 149 potassium chloride (Aune, \& Tanford, 1969). Concentrations of SC and MC in the stock solutions 150 were determined by drying at $104^{\circ} \mathrm{C}$ up to constant weight, taking into account the protein content in 151 the samples, which was determined by the Kjeldahl method for nitrogen determination in the proteins.

152 For all solutions, the required $\mathrm{pH}$ value (7.0) was obtained by addition of $0.1-0.5 \mathrm{M} \mathrm{NaOH}$ or $\mathrm{HCl}$.

153 In some experiments the phosphate buffer contained different amounts of $\mathrm{NaCl}$ to obtain the required 154 ionic strength values to study the effects of ionic strength on complex formation. Solutions of the 155 proteins were kept at least overnight in the fridge to allow for full hydration of the molecules.

156 To prepare mixed solutions of lys with SC, $\beta$-casein or MC with the required concentrations, weighed 157 amounts of the lys stock solution were added to a casein stock solution at $23^{\circ} \mathrm{C}$, followed by addition 158 of a weighed amount of the phosphate buffer and stirring for $1 \mathrm{~h}$. In the experiments to determine the 159 stability of the complexes with varying ionic strength, the ionic strength was adjusted after 160 preparation of the mixtures.

161 The lys/SC charge ratio $(\mathrm{ChR})$ is defined as the molar ratio of the total number of positive charges of 162 lys $\left(1,1946 \mathrm{mmol} \cdot \mathrm{g}^{-1}\right)$ to the number of negative charges of SC $\left(1,455 \mathrm{mmol} \cdot \mathrm{g}^{-1}\right)$ in the bulk solution. 163 The total amount of anionic groups of casein was calculated by Gurov (1982) on the basis of data 164 presented by Hipp, Groves, \& McMeekinin (1952). The total amount of cationic groups in Lys was 165 calculated based on data presented by Thompson (1955).

\section{Methods.}

167 Determination of $q_{\text {Onset }}, q_{\phi}, q^{*}, q_{\text {Max }}$, and $q_{\text {Set. }}$. The main parameters of the complexation process 168 were investigated by measuring turbidity at $500 \mathrm{~nm}\left(\tau_{500}\right)$ in the mixed solutions as function of the 
169

170

171

172

173

174

175

176

177

178

179

180

181

182

183

184

185

186

187

188

189

190

191

192

193

194

195

196

197

198

lys/casein weight ratio (q), $\mathrm{pH}$, and concentration of $\mathrm{NaCl}$ using a JASCO V-630 spectrophotometer, following the approach of Carlsson, Lines and Malmsten (2001). The error of the turbidity measurements is typically about $2 \%-3 \%$, only in the charge ratio range from 0.8 to 2.0 , the errors are markedly larger (6-8\%). First, the dependence of the turbidity of the mixed solutions on q was determined. Usually this dependence is characterized by the presence of specific q values (Carlsson, Lines, Malmsten, 2001) namely $q_{\text {Onset }}, q_{\phi}, q^{*}$, $q_{\text {Max }}$, and $q_{S e t}$ corresponding to respectively transitions from the absence of complexation to formation of water soluble complexes, from water soluble complexes to water insoluble complexes and their phase separation, maximal complexation, transition from formation of water insoluble complexes to water soluble complexes, and again the absence of complexation. The structure of the mixed solutions at these specific points was checked using an additional procedure. The transition between water soluble and water insoluble complexes ( $\mathrm{q}_{\phi}$ and $\mathrm{q}_{\phi}^{*}$ ) was determined by evaluating whether the turbidity value was changing with time, a change $>2 \%$ in 15 minutes was considered to indicate phase separation. The onset of formation of water soluble complexes ( $\mathrm{q}_{\text {onset }}$ ) was confirmed by determining the q value at which the size of the complexes, as determined by DLS, exceeds that of free SC by more than $10 \%$. The values of qset were established simply as the minimal q value at which the turbidity value of the Lys/SC or Lys/MC systems becomes equal to the turbidity value of a SC or MC solution with the same SC or MC concentration as the complex systems.

Light Scattering. Determination of the intensity and number size distribution functions of the complexes in lys/SC and lys/MC mixtures as well as the intensity-weighted distribution of hydrodynamic radii $\left(R_{\mathrm{h}}\right)$ of the macromolecular structures in SC solutions and their mixtures with lys was performed with an ALV/CGS-3 compact goniometer system (ALV GmbH, Germany). The system is equipped with an ALV-5000/EPP multi tau digital correlator, a HeNe laser operating at a wavelength of $632.8 \mathrm{~nm}$, and an avalanche photodiode detector. Buffer and samples of the binary buffer/SC and buffer/lys solutions were filtered through $0.22 \mu \mathrm{m}$ DISMIC-25cs (cellulose acetate) filters (Millipore) to remove dust particles. Subsequently, the samples were centrifuged for $30 \mathrm{~s}$ at $2000 \mathrm{~g}$ to remove air bubbles and placed in the cuvette housing, which was kept at $23^{\circ} \mathrm{C}$ in a toluene bath. The detected scattering light intensity was processed by digital ALV-5000 Correlator software. To process the DLS data the cumulant method was used. For each sample the measurement was repeated three times. 
In addition to DLS, SLS measurements were performed in the range $35^{\circ}-135^{\circ}$, and treated by the

200 Zimm method (Karayianni, Pispas, Chryssikos, and Gionis, 2011) to provide the radius of gyration 201 and molecular weight. The refractive index increment for both protein solutions was taken to be 0.190 $10^{3}\left(\mathrm{~m}^{3} \mathrm{~kg}^{-1}\right)$ (Antipova, Semenova, Belyakova, 1999; Eric Dickinson, 2005; Carrara, 2011). For each sample the measurement was repeated three times.

Electrophoretic Mobility. s-potential measurements of SC, MC and their complexes with lys at different lys/SC and lys/MC weight ratios (q) were performed at $23^{\circ} \mathrm{C}$ with a 90 Plus particle size analyzer (Brookhaven instruments Inc.) using a rectangular quartz capillary cell. $\varsigma$-potential was calculated automatically from the measured electrophoretic mobility, by using the Henry equation:

$$
\mathrm{U}_{\mathrm{e}}=\varepsilon \xi \mathrm{f} / 6 \pi \eta
$$

where $U_{e}$ is the electrophoretic mobility, $\varepsilon$ is the dielectric constant, $\eta$ is the viscosity and $\varsigma$ is the zeta potential. The Smoluchowski factor $f=1.5$ for large ratios of particle size to Debye length was used for the conversion of mobility into zeta potential. For each sample the $\varsigma$-potential was determined at least ten times and the average value is reported. It is important to note that $\varsigma$-potential measurements performed on mixed biopolymer solutions should be treated with caution, since the measured $\varsigma$ potential can represent both free and bound proteins (Mattison, Brittain, Dubin, 1995). The magnitude of the average value depends on the relative concentration, charge, and scattering intensity of the different molecular species. At pH 7.0 the mixed biopolymer solutions contained large insoluble complexes that are expected to scatter light much more strongly that any soluble biopolymer. We can therefore be fairly confident that the $\varsigma$-potential data presented for this $\mathrm{pH}$ value reflect the charges of the insoluble lys/casein complexes.

Fluorescence Anisotropy. Fluorescence anisotropy measurements were carried out on a PTI Quantamaster UV/vis (Photon Technology International) equipped with polarizers in the excitation and the emission path. Fluorescence anisotropy is calculated as follows:

$$
A=\frac{I_{\|}-I_{\perp}}{I_{\|}+2 I_{\perp}}
$$


with $A$ the fluorescence anisotropy and $I_{\|}$and $I_{\perp}$ the intensity of the fluorescent light polarized in the parallel and perpendicular direction, respectively (Lakowicz, 2006). Fluorescently labeled lys was prepared by slowly adding Atto 647 N (ATTO Tec. Germany) dye stock solution (approximately 1 $\mathrm{mg}$ in $0.5 \mathrm{~mL}$ phosphate buffer) to the stirred $0.02 \mathrm{wt} \%$ lys solution and subsequently storing the solution containing lysozyme and Atto $647 \mathrm{~N}$ dye at $5^{\circ} \mathrm{C}$ during 3 days. The conjugate was separated from not reacted reagent using a Sephadex G-25 gel filtration column (GE Healthcare, Uppsala, Sweden) equilibrated with a phosphate buffer $(\mathrm{pH} 7.0, I=0.01)$. This way, a labeled solution with an absorption value at $647 \mathrm{~nm}$ of approximately 0.36 was obtained. All measurements were performed at $647 \mathrm{~nm}$ and the excitation wavelength was $642 \mathrm{~nm}$.

Construction of Binding Isotherms. SC and MC were dissolved in a phosphate buffer $(I=0.01, \mathrm{pH}$ 7.0) in a concentration of $2 \cdot 10^{-3} \mathrm{wt} \%$. Lys was dissolved in the same buffer. Prior to experiments the pH was carefully corrected with $0.01 \mathrm{M}$ sodium hydroxide to 7.0 and the exact concentration was determined. Samples of SC or MC and lys (both labeled and nonlabeled) were mixed to obtain different weight ratios ( $\mathrm{mg}$ lys/mg casein), all with a casein concentration of $10^{-3} \mathrm{wt} \%$. Labeled and nonlabeled lys was assumed to bind identically to casein. Binding isotherms were constructed from the fluorescence anisotropy measurements. All points of the binding isotherms were averages of five measurements on different samples. The observed fluorescence anisotropy $\left(A_{\mathrm{obs}}\right)$ is the average of the 241 fluorescence anisotropy of the free $\left(A_{\mathrm{f}}\right)$ and bound $\left(A_{\mathrm{b}}\right)$ lys (Lakowicz, 2006).

$$
A_{o b s}=\left(f_{b} A_{b}+f_{f} A_{f}\right)
$$

243 with $f_{\mathrm{f}}$ and $f_{\mathrm{b}}$ the fraction of free and bound lys, respectively. $A_{\mathrm{f}}$ is determined in a sample that contains 244 both casein and lys and has an ionic strength of 0.3 . At these conditions there is no complex formation 245 between SC and lys and MC and lys and the measured fluorescence anisotropy was that of free lys. 246 The fluorescence anisotropy of bound lys, $A_{\mathrm{b}}$, was determined by taking the maximum value for the 247 fluorescence anisotropy throughout all the experiments.

248 Microscopy observations during complexation have been performed in bright-field using an 249 Olympus BX51W1 fixed stage microscope equipped with a high resolution CCD-camera 
(1000x1000 pixels, C-8800-21, Hamamatsu). After complexation, the morphology of lys/casein 251 mixtures did not change with time for durations of at least 30 minutes. Hence, steady state images 252 are shown.

253 Fluorescent imaging was performed using a multi-beam confocal microscope (VisiTech, UK), 254 equipped with an oil-immersion objective (x20, 0.85 NA, Olympus, Japan) using $532 \mathrm{~nm}$ and 642 $255 \mathrm{~nm}$ as excitation wavelengths. Full-frame (512x512 pixel resolution) images were acquired at $2562 \mathrm{~Hz}$. SC and MC were fluorescently labeled before imaging by storing casein solutions containing 257 Rhodamine $\mathrm{B}$ dye at $5^{\circ} \mathrm{C}$ during 3 days, whereas the lys solution containing Atto $647 \mathrm{~N}$ dye 258 (ATTO Tec. Germany) was kept under the same conditions. This labeling allowed to spectrally 259 separate the signal from SC (yellow) and lys (orange). Images were combined using ImageJ 260 v1.43r software (http://rsb.info.nih.gov/ij/).

CD measurements of a lys solution and of SC/lys and MC/lys mixtures were performed using a

262 Chiroscan Applied Photophysics instrument equipped with a temperature controlling unit. A 263 quartz cuvette of $0.1 \mathrm{~cm}$ light path length was filled with the sample solution. Circular dichroism spectra were recorded in the range from 195 to $250 \mathrm{~nm}$ at an interval of $0.2 \mathrm{~nm}$. The solutions were scanned at a rate of $50 \mathrm{~nm} / \mathrm{min}$ using a $2 \mathrm{~s}$ time constant, with a sensitivity of $20 \mathrm{mdeg}$ and a step resolution of 0.1 . The mean contents of helix, beta sheet and random structures were calculated with the SOMCD method which is an update of the k2D algorithm (Unneberg Merelo, Chacón, Morán, 2001). Four scans were averaged to obtain one spectrum. The experimental error was approximately $2 \%$.

Fluorescence spectroscopy. Fluorescence emission spectra between $300 \mathrm{~nm}$ and $450 \mathrm{~nm}$ were recorded on a RF 5301 PC Spectrofluorimeter (Shimadzu, Japan) at $23{ }^{\circ} \mathrm{C}$ with the excitation wavelength set to $280 \mathrm{~nm}$, slit widths of $3 \mathrm{~nm}$ for both excitation and emission, and an integration 273 time of $0.5 \mathrm{~s}$. The fluorescence intensity was corrected for absorption of excitation light and re274 absorption of emitted light to decrease the inner filter effect using the relationship (Weiping, 


$$
F_{c o r}=F_{o b s} \times e \frac{A_{e x}+A_{e m}}{2^{277}}
$$

where $F_{c o r}$ and $F_{o b s}$ are the corrected and observed fluorescence intensities respectively, and $A_{e x}$ and

$A_{e m}$ are the absorptions of the systems at the excitation and the emission wavelength, respectively.

The reported intensity values are the corrected fluorescence intensities. The experimental errors were approximately $2 \%$.

Phase analysis. The yields of the macromolecular components in the complex phase were determined by measuring the masses of the complex phase and the supernatant, and the total concentrations of biopolymers in these phases after centrifugation and subsequent separation of the phases. First, the total concentrations of SC and lys or MC and lys in the complex phase and the supernatant were determined by measuring the dry weight residue, after subtraction of the dry weight of the solvent (phosphate buffer, $I=0.01 \mathrm{M}$ ). Subsequently, the concentrations of SC or $\mathrm{MC}$ in the complex phase were determined by measuring the absorption values at $647 \mathrm{~nm}$ for solutions of the complex phase containing fluorescently labelled SC or MC in phosphate buffer in the presence of $0.5 \mathrm{M} \mathrm{NaCl}$. To that end, first, solutions of $\mathrm{SC}$ or MC containing Atto $647 \mathrm{~N}$ dye were kept at $5^{\circ} \mathrm{C}$ during 3 days for complete fixation of the dye onto casein. After that, SC was precipitated from solution by acidation up to $\mathrm{pH} 4.6$. The excess of Atto $647 \mathrm{~N}$ dye was removed from the precipitate by washing in distilled water at $\mathrm{pH} 4.6$, and after centrifugation, the protein was dissolved in phosphate buffer, and its concentration was determined as described above. In the case of $\mathrm{MC}$, the excess dye was removed by precipitation during centrifugation at $8000 \mathrm{~g}$ for $30 \mathrm{~min}$ at $23^{\circ} \mathrm{C}$ and subsequent washing in the phosphate buffer, and its concentration was determined as 298 described above. Finally, the concentration dependencies of the absorption at $647 \mathrm{~nm}$ for SC/Atto $647 \mathrm{~N}$ and MC/Atto $647 \mathrm{~N}$ solutions were determined. These calibration curves were used for the determination of the SC and MC concentrations in the complex phase after its disolution in the phosphate buffer containing $0.5 \mathrm{M} \mathrm{NaCl}$. Finally, the concentrations of lys in the complex phase of 
lys/SC and lys/MC mixtures were established by subtraction of the concentration of SC or MC in

303

304

305

306

307

308

309

310

311

312

313

314

315

316

317

318

319

320

321

322

324 the complex phase from the total concentration of biopolymers in this phase. The experimental errors were approximately $8-10 \%$.

\section{RESULTS AND DISCUSSION}

\section{Characterization of complexation at $\mathrm{pH} 7$ and ionic strength 0.01}

Determination of qonset, $q_{\phi}, q^{*} \phi, q_{\text {Max }}$, and $q_{\text {Set }}$ for Lys/SC system

To map out how the weight ratio of the proteins and the mixing conditions affect the formation and solubility of lys-casein complexes, the complexation process was first investigated in phosphate buffer at $\mathrm{pH} 7.0$ and ionic strength $I=0.01$ by measuring the turbidity of the mixed solutions. Turbidity in mixed protein solutions originates from the formation of complex particles or structures, and varies with the concentration and size of these particles.

Figure 1a,b shows $\tau_{500}$ values as a function of both the lys/SC weight ratio (q), and lys/SC charge ratio $(\mathrm{ChR})$ of the complex mixtures. Since complexation depends on whether the concentration of casein in the complex system or the total protein concentration is kept constant, in the first case (Fig 1a) the concentration of $\mathrm{SC}$ in the complex system $\left(\mathrm{C}^{\mathrm{M}}{ }_{\mathrm{SC}}\right)$ was variable at constant total protein concentration $\mathrm{C}^{\mathrm{M}}$ Tot $=0.02 \mathrm{wt} \%$, whereas in the second case (Fig 1b) the concentration of SC in the complex system was constant $\mathrm{C}^{\mathrm{M}} \mathrm{SC}=0.01 \mathrm{wt} \%$.

\section{FIGURE 1}

As can be seen in Figure 1a,b, the turbidity values of the complex mixtures are much higher than the corresponding values of the pure component solutions $(\sim 0.008)$. This confirms that complexation is actually taking place. The mixture behavior clearly depends on the charge ratio. The dependence has an extremal character with the maximum turbidity occuring at $\mathrm{ChR}=0.985$ or $\mathrm{q}=1.2$. Since at $\mathrm{pH} 7.0$ (experimental conditions) all the cationic groups of lys and all the anionic groups of SC are ionized, it can be concluded that the position of the absorption maximum in the complex lys/SC mixtures corresponds to a mutual compensation of the negatively charged groups of SC and positively charged groups of lys. Taking into account that the weight average molecular weight of lys is $14.3 \mathrm{kDa}$ (Rezwan, Meier, Gauckler, 2005) and that of SC is $320 \mathrm{kDa}$ (Antonov et al, 2009), we can roughly 
evaluate the "molar" ratio lys/SC in the complex phase at $\mathrm{ChR}=0.985$. A simple calculation shows that this ratio is $\sim 20: 1$. Since SC molecules are much larger than lys molecules complex formation between these biopolymers can be considered similar to that of other interacting weak polyelectrolytes (Sato, Nakajima, 1974; Sato, Maeda, Nakajima,1979) with largely dissimilar size namely as an association in which a few lys molecules (ligands) successively join one molecule of SC (nucleus). Turbidity measurements reveal five domains of q (Fig 1a,a',a") corresponding to (I) the absence of complexation, (II) soluble complex formation, (III) phase separation of an insoluble complex (Carlsson, Lines, Malmsten, 2001), (IV) suppression of phase separation, and (V) the absence of complexation. The transition from region I to region II is denoted "qOnset", the transition from region II to region III is denoted " $\mathrm{q}_{\phi}$ ", the transition from region III to region IV is denoted " $\mathrm{q}^{*}{ }_{\phi}$ ", and the transition from region IV to region $V$ is denoted " $\mathrm{qSet}$ ". The $\mathrm{q}_{\phi}$ and $\mathrm{q}^{*}{ }_{\phi}$ values are a measure of the complex stability and characterize the phase boundary.

The weight ratio values corresponding to $\mathrm{q}_{\text {Onset }}, \mathrm{q}_{\phi}, \mathrm{q}^{*}{ }_{\phi}$, and $\mathrm{q}_{\text {Set }}$ are $0.09,0.31,42$ and 165 respectively in the case in which $\mathrm{C}^{\mathrm{M}} \mathrm{SC}$ is variable (Fig 1a, a', a"). These values are approximately 30 times higher than those for the complexation process of lys with a strong polyelectrolyte such as dextran sulfate, which has been studied before at the same ionic strength (Antonov, Zhuravleva, Cardinaels, Moldenaers, 2015). Comparing the complexation behavior of mixtures obtained at different 348 conditions of mixing (Fig 1a and Fig 1b) shows that the qualitative dependence of $\tau_{500}$ on q is similar in the range of $\mathrm{q}$ from 0 to 1.2 with the values of qonset and $\mathrm{q}_{\phi}$ for the system in the case of $\mathrm{C}^{\mathrm{M}} \mathrm{SC}$ constant (Fig $1 \mathrm{~b}, \mathrm{~b}^{\prime}$ ) being 0.09 and 0.33 . Contrary to the low $\mathrm{q}$ range, for $\mathrm{q}>1.2$, significant 351 differences occur. In the complex mixtures with a variable $\mathrm{C}^{\mathrm{M}} \mathrm{SC}$ (Fig 1a), the solubility of the complexes grows steeply with increasing q ( $\tau_{500}$ decreases as function of $\left.q\right)$ whereas in the complex mixtures with a constant $\mathrm{C}^{\mathrm{M}}{ }_{\mathrm{SC}}($ Fig $1 \mathrm{~b})$ the decrease in turbidity $\tau_{500}$ and thus increase in complex 354 solubility with increasing $\mathrm{q}$ is limited. This difference is probably caused by a stronger aggregation of the complex particles in the latter mixtures, in which the SC concentration at high q value is larger. 
The results obtained for lys/SC mixtures in Figure 1a,b can be compared to the results for lys/MC mixtures that are presented in Figure $1 \mathrm{c}, \mathrm{d}$. Similar to the lys/SC mixtures, the complexation behavior of lys/MC mixtures also depends on $\mathrm{q}$ or $\mathrm{ChR}$. This dependence again has an extremal character with the maximum $\tau_{500}$ occuring at $\mathrm{q}=1.55$ or $\mathrm{ChR}=1.2$. The position of the absorption maximum in the complex lys/MC mixtures does not exactly correspond to the condition of mutual compensation of the negatively charged groups of MC and positively charged groups of lys. This could be caused by a less good accessibility of some of the negatively charged groups of MC, requiring excess lys for interaction. Taking into account that the weight average molecular weight of lys is $14.3 \mathrm{kDa}$ and that of MC is equal to $250000 \mathrm{kDa}$ (Holt et al, 2013; Dalgleish et al, 2004), we can roughly evaluate the "molar" ratio lys/MC in the complex phase at $\mathrm{ChR}=1.26$. A simple calculation shows that this ratio is $\sim 26000: 1$.

Figure 1 shows that the weight ratios corresponding to qonset and $\mathrm{q}_{\phi}$ are much lower for lys/MC mixtures $\left(0.0027\right.$, Fig $\left.1 c^{\prime}\right)$ than the corresponding values for the lys/SC mixtures $\left(0.09\right.$, Fig $\left.1 \mathrm{a}^{\prime}\right)$. This difference can be attributed to the larger size and much higher molecular weight of MC as compared to SC. Such behavior is typical for the bridging flocculation of colloidal particles by polyelectrolytes. Comparison of the solution behavior of the complex lys/MC and lys/SC mixtures obtained at constant $\mathrm{C}^{\mathrm{M}}$ cas values shows that at $\mathrm{q}>\mathrm{q}_{\max }$ aggegation of the complex particles is more pronounced for the lys/MC system (Fig 1b,d), i.e when the casein molecules are present in the mixture in micellar form.

Electrophoretic mobility and phase analysis. To determine the effective surface charge of the formed complexes, electrophoretic light scattering (ELS) measurements were performed on the lys/SC and lys/MC mixtures. The $\varsigma$-potential of the complex mixtures, determined as a function of the lys/casein weight ratio (q), is shown in Figure 2a. Upon self-assembly of lys and casein, the

\section{FIGURE 2}

negative charge of casein is rapidly neutralized, and the surface charge of the formed complexes turns into positive values at higher q ratios. The $\varsigma$-potential of the SC mixtures starts to increase later than 
that of the MC mixtures. This can be an indication that the lysozyme can interact with all charges in

384 SC whereas in MC it will first interact with the charges at the surface. For lys/SC mixtures, complete neutralization of the negative charge takes place at $\mathrm{q}=1.19(\mathrm{ChR}=0.985)$, i.e. at the $\mathrm{q}$ ratio corresponding to the maximal complexation as determined by the turbidity measurements in Figure 1a. This result points to the dominating role of the electrostatic forces in the complexation process, and confirms that there is a good accessibility of all charged biopolymer groups for interaction. On the other hand, for lys/MC mixtures, complete neutralization of the negative charges only takes place at a higher $\mathrm{q}=1.48$ or $\mathrm{ChR}=1.26$. In other words, the amount of lys necessary for the neutralization of 391 the negative charge is larger as compared to that for lys/SC mixtures. In the range of $\mathrm{q}>\mathrm{q}_{\max }$, the ELS results show that the $\varsigma$-potential is dependent on the dispersion state of the casein molecules (molecularly dispersed associated state of SC versus colloidal state of MC).

394 The $\varsigma$ - potential of lys/SC mixtures exhibits increasingly positive values when the lys concentration, and thus charge ratio, increases. This trend points to the fact that at higher charge ratio values each $\mathrm{SC}$ chain interacts with a larger quantity of lys molecules. As a result, the degree of neutralization of the positive charges of the lys chain decreases. In lys/MC mixtures, we observed a plateau in the $\varsigma$ potential for q-values between approximately 1.5 and 10, and only a further increase of q resulted in an appreciable increase of the $\varsigma$-potential. At high q values, the complexes formed in the lys/MC system thus exhibit reduced effective positive charge values as compared to the corresponding values 401 for the lys/SC system. This observation is in agreement with our conclusion made above that large MC particles need excess lys for complete neutralization of the complexes. In conclusion, the results obtained from electrophoretic mobility indicate that complexation and probably allocation of the biopolymers within the formed complexes at higher q values are different for lys/SC versus lys/MC mixtures.

406 Further, phase analysis was used to provide insight in the composition of the complex biopolymer particles that are formed in the lys/SC and lys/MC mixtures. Figure $2 \mathrm{~b}$ presents the lys/casein weight ratio in the biopolymer rich complex phase $\mathrm{q}^{*}$ as well as the yield of the complex (mass percentage) 
in the biopolymer rich complex phase as a function of the weight ratio $\mathrm{q}$ of lys and casein, both for

$410 \mathrm{lys} / \mathrm{SC}$ and lys/MC mixtures. Phase analysis measurements for lys/SC mixtures reveal two domains, 411 depending on the $\mathrm{q}$ ratio; domain 1 for $\mathrm{q}$ values from 0 to 1.2 and domain 2 , for $\mathrm{q}>1.2$. The first 412 domain can, at first approximation, be characterized by a constant lys/cas weight ratio $\mathrm{q}^{*}$ in the 413 complex phase, whereas in the second domain a sharp increase of $\mathrm{q}^{*}$ is observed when the charge 414 ratio increases. Concomitantly, the yield of the water insoluble complex reaches a maximum value (89 \%) at $\mathrm{q}=1.2$, and then decreases sharply down to $10 \%$ when $\mathrm{q}$ increases further. Since the 416 composition of the lys/SC complexes in the first domain only weakly depends on the composition of 417 the initial mixture, and the yield of the complex phase increases with increasing ChR, we propose an "all or none" type complex formation mechanism, which has already been established (Michaels, Mir, Schneider, 1965; Michaels, Falkenstein, Schneider, 1965) for oppositely charged polyelectrolyte systems. This implies that the reactivity of the SC chain partially covered by lys may be considered higher than that of free casein chains. Therefore, completely neutralized complexes and completely free casein coexist in the complex solution. In the second domain ( $\mathrm{q}>1.2$ in fig $2 \mathrm{~b})$, a higher content of lys in the complex mixture (higher ChR) directly translates into a higher content of lys in the complex phase. In other words, the number of lys molecules interacting with each casein chain increases, leading to overcharged lys/SC complexes, which hinders their aggregation and increases their solubility. The latter is reflected by the reduced yield of the complex phase. Therefore, the formed complexes consist of a decreasing amount of SC chains and a relatively high content of 428 lys.

429 In contrast to lys/SC mixtures, phase analysis measurements for lys/MC mixtures reveal a rather 430 constant value of the lys/MC weight ratio $\mathrm{q}^{*}$ in the complex phase, over the whole range of q values 431 studied. The composition of the lys/MC complexes thus depends only weakly on the composition of the initial mixture. In other words, the number of lys molecules interacting with each MC micelle 433 does not change significantly with increasing q ratio. This is in agreement with the plateau in the $\varsigma$ - 
434 potential in this range of q-values. Nevertheless, the yield of the water insoluble complex reaches a 435 maximum $(97 \%)$ at $\mathrm{q}=1.5$, which corresponds to the turbidity results in Fig. 1c.

436 Binding constant. The binding isotherms for lys/SC and lys/MC mixtures determined from 437 fluorescence anisotropy measurements are presented in Figure 3a.

\section{FIGURE 3}

439 These isotherms show two characteristic regions at $\mathrm{pH}$ 7.0: (i) a first region where binding sharply 440 increases; (ii) a saturation region that appears at the largest lysozyme concentrations. In order to 441 determine the binding constants for lys/SC and lys/MC respectively, the binding isotherms were fitted 442 with a Langmuir binding isotherm, which assumes independent identical binding sites:

$$
v=\frac{K L}{1+K L}
$$

444 with $v$ the binding ratio, $K$ the binding constant and $L$ the concentration of free ligand. Results of 445 the fits are presented in Table 1. For both systems, the binding isotherms are relatively well described 446 by the Langmuir isotherm. The binding constant for lys/SC systems $\left(3.3 \times 10^{2} \mu \mathrm{M}^{-1}\right)$ is only 1.4 times 447 larger than that of $1 \mathrm{ys} / \mathrm{MC}$ systems $\left(2.4 \times 10^{2} \mu \mathrm{M}^{-1}\right)$, indicating a similar affinity of both proteins to 448 bind lys.

\section{Table 1}

450 Size of the complexes. To obtain information about the sizes of the complex particles, DLS measurements were performed on a series of Lys/SC and lys/MC mixtures at a constant total concentration of biopolymers $(0.02 \mathrm{wt} \%)$, and in a wide q range (from 0.2 to 45.4 or ChR from 0.16 to 37.6). Our preliminary experiments on binary solutions showed that the intensity size distribution 454 functions and the number size distribution functions for SC and MC were not dependent on the concentration, at least in the range from $10^{-4} \mathrm{wt} \%$ to $0.1 \mathrm{wt} \%$. The average size for $90 \%$ of the SC molecules was in the range of 4.6-5.2 nm (data not shown), which is in accordance with known data

457 (Panouillé, Nicolai, Durand, 2004). A small amount of SC associates with an average radius of 63 $\mathrm{nm}$ was also registered. The average size of MC particles was $150 \mathrm{~nm}-160 \mathrm{~nm}$ (data not shown), a 
monomer was $1.9 \mathrm{~nm}$ (data not shown), in accordance with our earlier work (Antonov et al, 2015) and other known data (Parmar,\& Muschol, 2009; Valstar, Brown, Almgren, 1999). In addition, some aggregates were measurable as well; the volume contribution of these aggregates was measured to be $0.2 \%$. It is well known that such aggregates are extremely difficult to avoid, especially at $\mathrm{pH} 7.0$ (Sophianopoulos, Vanholde, 1961).

The scattering intensity size distribution functions and the number size distribution functions for the complex lys/SC and lys/MC mixtures at a constant total concentration of biopolymers $(0.02 \mathrm{wt} \%)$ are presented in Figure 4a,b, and Figure 4c,d respectively. The intensity autocorrelation functions

\section{FIGURE 4}

indicated that the data is good enough to calculate the mean size of the particles. The average radius of the complex particles as a function of the ChR in these systems is shown in Figure 4a',b' and Figure $4 \mathrm{c}^{\prime} \mathrm{d}$ ' for the scattering intensity average size and the number average size respectively. As can be seen in Fig. 4a, in the presence of even a very small amount of lys in the SC solution (at $\mathrm{q}=0.2$ or $\mathrm{ChR}=0.16$ ), the dominant peak shifts to an average radius of $51 \mathrm{~nm}$. For most $\mathrm{q}$ values, the complex particles are characterized by a narrow size distribution (Fig 4c). The asymmetry coefficient (Z) of the complex associates at low q values (under conditions of relatively low aggregation of complex particles) was estimated by the Debye method based on the determination of the scattering intensity I at two angles $\left(45^{\circ}\right.$ and $\left.135^{\circ}\right)$, and subsequent extrapolation of the ratio $\mathrm{I}\left(45^{\circ}\right) / \mathrm{I}\left(135^{\circ}\right)$ to zero concentration (Storey, B. T.; Lee, Papa, Rosen, Simon, 1976). The complex associates are symmetric with $\mathrm{Z}$ values equal to 0.88 for the lys/SC system and 0.91 for the lys/MC system.

The sizes of the complex lys/SC particles and their polydispersity increase significantly when the $\mathrm{q}$ values increase reaching a maximum value of $629 \mathrm{~nm}$ for $\mathrm{q}=1.19$ or $\mathrm{ChR}=0.99$, and decrease again sharply (up to $285 \mathrm{~nm}$ ) with further increase of the q ratio up to 45.4 or $\mathrm{ChR}=37.6$. The results obtained are in agreement with the data of the turbidity and zeta potential measurements as well as phase analysis (Fig 1a and 2a,b). The maximal size of the particles occurs at the $\mathrm{q}$ and ChR value corresponding to the maximal turbidity of the system and maximal yield of the complex, which 
coincides with the conditions where the surface charge is close to zero (conditions of mutual

487 compensation of the negative and positive charges). The main trend of the size evolution of the 488 complex particles in lys/MC systems with q is almost the same as that for the lys/SC system (Fig 4b) except for a few important aspects. The MC form (due to its larger size) results in larger complexes

in the complete charge ratio range, and the formed particles are more polydisperse in the complete $\mathrm{q}$ range studied. The maximal size of these particles reaches $1050 \mathrm{~nm}$ at $\mathrm{ChR}=1.24$, i.e. at the $\mathrm{ChR}$

492 value corresponding to the maximal absorption of the system and its zero $\varsigma$ - potential value (Figs 1c 493 and 2a).

Structure of the complexes. Confocal laser Scanning microscopy (CLSM) is a very common method for in vivo studies of protein localization at different tissue depths (Sarmento, Ribeiro, Veiga, 496 Sampaio, Neufeld, Ferreira, 2007). CLSM has also been widely used to image protein distributions 497 or their diffusion on polyelectrolyte surfaces (Jewell et al, 2007) or in polyelectrolyte-protein capsules (Sarmento et al, 2007), coacervates (Liu, Cao, Ghosh, Rousseau, Low, Nickerson, 2010) or particles (Park, Na, 2009). We applied fluorescent imaging in order to monitor the distribution of lys within lys/SC and lys/MC complexes at different $\mathrm{ChR}$. The data obtained for the first system are 501 presented in Figure 5a-c.

\section{FIGURE 5}

Three characteristic compositions of the complex system were considered namely $\mathrm{ChR}=0.41$, corresponding to an excess of $\mathrm{SC}, \mathrm{ChR}=1.0$, corresponding to the maximal yield of the complex according to the phase analysis and turbidity measurements (Figs 1 and 2b), and finally, a composition characterized by an excess of lys in the complex system $(\mathrm{ChR}=3.9)$. It can be seen that at a low charge ratio (excess of SC in the complex mixture) the intensity signal mainly originates from SC (yellow), whereas the signal from lys (orange) is uniformly distributed inside the complex particles (Fig 5a). At $\mathrm{ChR}=1.0$, corresponding to the maximal yield of the complex, the orange signal indicating the 510 presence of lys becomes slightly more pronounced on the periphery of the complex particles pointing 511 towards a partial redistribution of this protein in the complex particle (Fig 5b). Finally, at $\mathrm{ChR}=3.9$, 
512 i.e. with an excess of lys in the complex system, a high intensity signal from the positively charged

513 lys protein can be observed on the periphery of the complex particle in the form of an orange ring

514 (Fig 5c). The radius of this ring with a high density of lys cationic groups is about $15 \%$ of the radius 515 of the complex particle.

516 The results obtained for lys/MC systems are shown in Figure 6. We analyzed the behavior of the 517 complex systems at different compositions characterized by ChR ratios ranging from 0.16 to 4.1 . It

\section{FIGURE 6}

should be noted that at lower ChR values, the intensity signal of the labelled lysozyme is too weak to assess whether interactions initially occur with the charges at the surface of MC, as suggested by the ELS results. However, the images show without doubt that in contrast to lys/SC complex particles, the particles of the lys/MC system do not exhibit a peripheral layer saturated with lys molecules at any $\mathrm{ChR}$ value above 0.15 . In this system, both proteins distribute within the particles more or less uniformly. Thus, the results of confocal microscopy clearly show that the localization of lys within the complex particles depends on the state of dispersion of the casein molecules (molecularly versus colloidally dispersed state). For the lys/SC system the distribution is dependent on the $\mathrm{ChR}$ of the complex system, whereas for the lys/MC system the localization of lys is only weakly dependent on the ChR, at least in the range of charge ratio values studied. The results obtained can be explained on the basis of a theory for complexes of oppositely charged hydrophilic and hydrophobic macromolecules forming a two-phase structure (Vasilevskaya, Leclercq, Boustta, Vert, Khokhlov, 2007). The inner part of the complex contains monomer units of both macromolecules, whereas the exterior part consists exclusively of monomer units of the hydrophilic macromolecules. The formation of this protective layer is promoted by the energetic gain when the hydrophilic monomer 534 units are exposed to the surrounding solvent rather than the hydrophobic core. On the contrary, the factor preventing the formation of such a layer is the Coulomb attraction between the excess of negative and positive groups in the internal and external parts, respectively, of the intermolecular polyelectrolyte complexes. The balance of these two main factors determines the presence and width 
of the protective external layer. Lys and casein macromolecules have different affinities to water and

539 different densities of ionic groups along their chain. It is well known that caseinate is a highly

540 hydrophobic protein due to its peculiar charge distribution and largely sized hydrophobic domains

541 (Hand Book of Food Science, 2005), whereas lys is a small hydrophilic protein (Hamill, Wang, Lee,

542 2005). Therefore complexes of such macromolecules can form a core-shell structure in accordance

543 with the theory of Vasilevskaya et al (2007). The absence of such a core-shell structure for lys/MC

544 complexes can be due to the dominance of the Coulomb attraction between excess negative and

545 positive groups in the internal and external parts, since casein micelles are already surrounded by a

546 shell with a higher affinity towards water (McMahon, Oommen, 2013).

547 To provide a more detailed picture of the structure of the complexes, we examine next the

548 dependencies of the radius of gyration $\left(\mathrm{R}_{\mathrm{g}}\right)$ of the complex particles and the molecular weight of the

549 complexes on ChR, determined from SLS measurements. The $\mathrm{R}_{\mathrm{g}}$ values and the apparent weight 550 average molecular weight, $\mathrm{M}_{\mathrm{w}}$, as functions of the $\mathrm{ChR}$ for the complex lys/SC mixtures at $\mathrm{pH} 7$ and $551 I=0.01$ are presented in Figure $7 \mathrm{a}, \mathrm{b}$. It can be seen that both dependencies show an extremal

\section{FIGURE 7}

character with a maximum at $\mathrm{ChR} \approx 1.0$. It should be noted that the sizes and masses of the complex particles at $0.8<\mathrm{ChR}<4$ are too large to determine them precisely, therefore these molecular parameters were determined only roughly and are denoted in Figure 7 by a dashed line. For these cases the evaluation of $\mathrm{M}_{\mathrm{w}}$ from $\mathrm{R}_{\mathrm{g}}$ was performed on the basis of a known calibration curve providing the relation between $\mathrm{R}_{\mathrm{g}}$ of different proteins and their molecular weight (Takahashi,

558 Kubota, Kokai, Izumi, Hirata, Kokufuta, 2000). The data clearly indicate the extremal character of 559 the dependencies of $\mathrm{R}_{\mathrm{g}}$ and the molecular weight of the complexes on the ChR. Since the molecular 560 weight of casein micelles is very high $(\approx 250000 \mathrm{kDa})$, determination of this parameter for large 561 lys/MC particles by SLS is not feasible.

562 The CLSM, SLS, and phase analysis data allow to propose a schematic structure of the complexes.

563 Based on the $\mathrm{M}_{\mathrm{w}}$ values of the lys/SC complexes at $\mathrm{ChR=1.0} \mathrm{(i.e.} \mathrm{under} \mathrm{conditions} \mathrm{of} \mathrm{mutual}$ 
compensation of the positive charges of lys and negative charges of SC) when the molar ratio of lys and SC in the complexes is 20:1, the number of lys chains and SC molecules comprising the complexes can be approximated. As depicted schematically in Figure 8, at $\mathrm{ChR}=1.0$ each complex consists of several hundred SC chains and several thousand lys molecules. Under these conditions,

\section{FIGURE 8}

each SC chain interacts with several lys molecules forming an interpolymer complex. Because of charge neutralization, these interpolymer complexes exhibit reduced solubility and thus associate to form large aggregates, in accordance with the complexation mechanism proposed by Dubin and coworkers (Takahashi et al, 2000; Tsuboi, Izumi, Hirata, Xia, Dubin, Kokufuta, 1996). Complete neutralization of the countermacroions of the proteins within the complex particles in the ChR range from 0.16 to 0.985 occurs by a more or less uniform distribution of the SC and lys chains in the complex particle (Fig 5). This fact is in agreement with the results of the phase analysis of the complex phase (Fig $2 \mathrm{~b}$ curve 2 ), showing that the weight ratio of the proteins within the complex remains more or less constant. At $\mathrm{ChR}>1$, when the surface charge of the complexes becomes positive, the structure of the lys/SC complexes changes significantly. An excess of lys in the complex system leads to the formation of an outer shell on the particles comprising mostly of lys molecules. At the same time, the center part of the complex particles still contains completely neutralized countermacroions of the proteins. In other words, the number of lys molecules interacting with each cas chain increases, leading to limited charge neutralization, which hinders the aggregation of the interpolymer complexes (Fig 1). Therefore, on average the formed complexes consist of a decreasing number of SC chains and have decreased $R_{h}$ and $M_{w}$ values. These conclusions are in agreement with the phase analysis (Fig 2b), which shows that with increasing amount of lys in the mixture, its relative content in the complex phase increases. On the other hand, in the lys/MC system, different structural changes of the complex particles with increasing ChR take place. By comparing the CLSM data for the lys/MC complexes obtained at ChR between 0.16 and 4.1, i.e. under conditions of excess of MC as well as 
under conditions of excess of lys, neutralization of the countermacroions of the proteins, within the 591 complex particles takes place with a more or less uniform distribution (Fig 6). Hence, an excess of 592 lys should be accumulated in the supernatant of the complex system, and the lys/MC weight ratio in 593 the complex phase should not change significantly with q. The results of the phase analysis of the 594 complex phase and supernatant (Fig 2b) indeed confirm this fact.

pH stability of the complexes at different ionic strength.

Turbidimetric titrations of lys/SC mixtures at various ionic strengths were performed from $\mathrm{pH} 7$ into the alkaline region to obtain more information about the interaction of these biopolymers. A typical result is given in Figure 9 a. For the lys/MC system, these titrations were not done

\section{FIGURE 9}

602

because $\mathrm{MC}$ decomposes in alkaline solutions. Absorption measurements reveal two domains of $\mathrm{pH}$ corresponding to (I) the absence of interaction $\left(\tau_{500} \approx 0\right)$, and (II) phase separation of an insoluble complex $\left(\tau_{500}>0\right)$. The transition from region I to region II is denoted " $\mathrm{pH}$ Set". The results of different turbidimetric titrations are presented in Figure $9 b$. Figure 9c presents the dependence of the $\mathrm{pH}_{\text {Set }}$ values of the system as a function of ionic strength. Lys can associate with SC at pH 11.29, at which its net charge is slightly negative (Sato, Mattison, Dubin, Kamachi, and Morishima, 1998), because positively charged residues (11 arginyl residues with pKa value of 12.5) locally exist even at this $\mathrm{pH}$. Park et al. also reported (Park, Muhoberac, Dubin, Xia, 1992) that lys interacted with the anionic polyectrolyte PAMPS above its $\mathrm{pI}$ when the net charge of lys was $-2.6 \pm 1$ in $0.1 \mathrm{M} \mathrm{KCl}$. The data obtained shows that the $\mathrm{pH}_{\text {Set }}$ values significantly decrease (from 11.29 to 9.02) with increasing ionic strength from 0.01 to 0.09 . These observations once more imply that the interaction between lys and $\mathrm{SC}$ is governed by electrostatic interactions.

\section{Protein structure within the complexes.}

The preservation of the enzymatic activity, which is directly correlated with the protein conformation, is an issue of major importance in most applications involving protein/polyelectrolyte 
and protein/protein complexes. For this reason CD spectroscopy measurements in the far UV region

618 were performed to study possible structural changes of lys within the complexes with casein (SC or

619 MC) and that of casein within the complexes with lys. Since from all casein fractions only $\beta$-casein

620 has a more or less expressed secondary structure, possible structural changes of $\beta$-casein in the 621 presence of different amounts of Lys were monitored. The results are presented in Figures 10 and 11.

\section{FIGURE 10}

The CD spectrum of lys exhibits two negative peaks in the far-UV region at 208 and $222 \mathrm{~nm}$ (Fig 10a), which is contributed by $\mathrm{n} / \pi^{*}$ transitions of the peptide bond of the $\alpha$-helix (Woody, 1995). The elasticity at $220 \mathrm{~nm}$ is a standard measure of the helical content of a protein. On the basis of the analysis carried out using the SOMCD method, which is an update of the k2D2 algorithm, the secondary structure of lys in the complex lys/SC systems is estimated. At $23^{\circ} \mathrm{C}$ lys contains $28.1 \% \alpha-$

628 helical structure, 9.0\% $\beta$-sheets and 62.9\% random structure. Even an insignificant presence of SC in the lys solution at $\mathrm{q}=10$ results in an appreciable decrease of the negative Cotton effect at $222 \mathrm{~nm}$.

630 The content of the $\alpha$-helical structure in lys decreases to $19.2 \%$. With a further decrease of the $q$ 631 values from 10 to 1.0 (increase in SC content in the complex mixture) the negative band at $222 \mathrm{~nm}$ 632 decreases sharply in intensity. At charge ratio 1.0 the structure of lys becomes almost unordered. It 633 contains $5.4 \% \alpha$-helical structure, $7.0 \% \beta$-sheets and $87.6 \%$ random structure.

634 The $\beta$-casein spectrum in Figure 10b exhibits one negative peak in the far-UV region at $208 \mathrm{~nm}$, and 635 a shoulder at $222 \mathrm{~nm}$, indicative of the presence of a small amount of $\alpha$-helix structure (Greenfield, 636 2007). This spectrum is typical for $\beta$-casein: data of CD studies and FTIR spectroscopy suggest that $637 \quad \beta$-casein contains $10 \%-13 \% \quad \alpha$-helix and $13 \%-22 \% \quad \beta$-structures (Farrell, 638 Qi, Wickham, Unruh, 2002). Our data show a $\alpha$-helical content of $12 \%, 18 \% \beta$-sheets and $70 \%$ 639 random structure. When increasing q, starting from small q values (0.3), almost complete disruption 640 of the helical structure takes place and the protein structure transfers to an unordered one. The 641 negative band at $208 \mathrm{~nm}$ decreased further in intensity with the increase of $\mathrm{q}$ from 0.3 to 1.2 (increase 
642 in lys content in the complex mixture). Comparison of the CD spectra obtained for lys/MC systems

643 (Fig 11) with those of lys/SC systems (Fig 10) reveals a more significant effect of

644

645

FIGURE 11

$646 \mathrm{MC}$ on the secondary structure of lys. Actually, at q=10 the CD spectrum of lys in the lys/SC systems 647 shows a decrease in the content of the $\alpha$-helical structure from $28 \%$ to $19.2 \%$, whereas for the lys/MC system the CD spectrum indicates the formation of a completely unordered structure of lys within the complex.

Additionally, fluorescence spectroscopy was employed to investigate the protein structure within the complexes. Figure 12 shows the fluorescence emission spectra of lys and complex lys/SC and lys/MC systems after subtraction of the contribution from the fluorescence emission spectrum of SC. The wavelength of maximum

\section{FIGURE 12}

emission $\left(\lambda_{\max }\right)$ for lys was about $341 \mathrm{~nm}$. This fluorescence peak exclusively arises from six tryptophan residues of lys (Lakowicz, 1986; Kuramitsu, Kurihara, Ikeda, \& Hamaguchi, 1978) but 657 only two of them, Trp62 and Trp108 appear to dominate the fluorescence spectrum 658 (Nishimoto,Yamashita, Szabo, \& Imoto, 1998). When different amounts of SC were titrated into a 659 fixed concentration of lys, the fluorescence intensity of lys changed significantly (Fig 12a). On the 660 one hand, an addition of SC leads to a significant increase of the fluorescence intensity of lys. On 661 the other hand, a significant blue shift of the maximal emission wavelength from 341 to $337 \mathrm{~nm}$ was 662 observed (Fig 12a). The blue shift of the fluorescence maximum of lys in the presence of SC illustrates 663 the hydrophobic effect on Trp due to the direct complex formation of these proteins probably through 664 cooperative binding. The observed increase in the fluorescence intensity of lys in the presence of SC 665 is the result of insignificant conformation changes of the lys molecules. Fluorescence spectra of lys 666 in the presence of MC (Fig 12b) show a nonmonotonic dependence on the MC amount. The addition 667 of MC into the lys solution leads first to a significant decrease of the fluorescence intensity up to q 
668

669

670

671

672

673

674

675

676

677

678

679

680

681

682

683

684

685

686

687

688

689

690

691

692

693

values approximately equal to qMax corresponding to the maximal interaction in the complex system (Figs 1 and 2). This decrease in fluorescence intensity or fluorescence quenching is a result of a variety of intermolecular interactions, including excited-state reactions, molecular rearrangements, energy transfer, and ground state complex formation (Imoto, Forster, Repley, \&Tanaka. 1971). With further increase of the content of MC in the complex system the fluorescence intensity increases up to approximately the initial intensity of free lys.

In summary, CD spectra reveal a substantial effect of the complexation on the secondary structure of the proteins within the complex. For lys, a destruction of the ordered secondary structure occurs in both the lys/SC and lys/MC systems. In addition, also $\beta$-casein undergoes a spectacular change in secondary structure. However, the fluorescence intensity measurements indicate an absence of significant changes in the tertiary structure of lys after complexation with casein. Such "contradiction" between $\mathrm{CD}$ and fluorescence data is not exceptional. It was also observed, for example, by Lin, Zhao and Wang (2010) in their study of conformational changes and noncovalent complexes of myoglobin with ligands by electrospray ionization mass spectrometry, circular dichroism and fluorescence spectroscopy. Spectroscopic data presented in their work demonstrates two mechanisms of protein unfolding; one of them reduces the amount of helices in myoglobin without loss of tertiary structure, whereas the other one results in the loss of tertiary structure. Hence, the loss of the helix structure in lys within the lys/casein complex determined by CD spectroscopy and the absence of considerable changes in the tertiary structure of lys could be explained by an existence of different mechanisms of protein unfolding.

\section{Morphology of the complex system.}

The results presented above demonstrate that changing the state of the casein molecules and the ChR in lys/casein systems alters solubility, composition, surface charge, and structure of the complex particles, as well as the structure and allocation of the proteins within the complexes. In the present section, we consider the morphology of lys/SC and lys/MC systems as a function of ChR starting 
694 with association (aggregation) of small complex microparticles formed at q values slightly above 695 qOnset. Bright-field light microscopy was used to visualize the overall morphology of the particles in 696 the complex systems. This also provides an additional verification of the possible effect of the protein 697 labeling on the particles, which may play a role in CLSM. Representative images at selected ChR 698 values are presented in Figure 13. It should be noted that typical light microscopy only allows to 699 clearly FIGURE 13

701 resolve features with a size on the order of a $\mu \mathrm{m}$. Hence, this technique will allow to characterize the 702 aggregation behavior of the complex particles that are formed in the ternary mixtures.

703 For lys/SC, at a low ChR value equal to 0.08 (very close to the qonset value) formation of numerous 704 almost spherical small particles was observed. The particles did not aggregate with time, i.e. they are 705 characterized by a high aggregative stability. Starting from $\mathrm{ChR} \approx 0.12$ the particles form rod-like 706 aggregates by a head-to-tail mechanism. At $\mathrm{ChR \approx 0.16}$ these elements increase in length forming vermiform particles. With further increase of the $\mathrm{ChR}$ values up to $\approx 0.41-0.58$, growth of the complex particles in length is halted but smaller complex particles join the large vermiform particles from the sides resulting in the formation of a branched structure. At ChR=0.8-1.0 this type of morphology is supplemented by micelle like particles. Further growth of the ChR up to 10 leads to disaggregation 711 of the complex particles and a reverse development of the morphology. Increasing the SC 712 concentration in the system from $0.025 \mathrm{wt} \%$ to $0.1 \mathrm{wt} \%$ does not alter the qualitative morphology development of the complex system as a function of ChR (data not shown). Also in the lys/MC system, typical morphological changes occur. At ChR values from $\approx 0.01$ to 0.25 the morphology is qualitatively the same as for lys/SC systems at $\mathrm{ChR}=0.08$, i.e. formation of small spherical particles takes place. At a higher $\mathrm{ChR}(\approx 0.3-0.66)$ these particles coalesce with each other

717 forming aggregates. In contrast to lys/SC systems these aggregates are characterized by an 718 insignificant degree of asymmetry. At ChR values $\geq 1.0$ they associate, forming a droplet like morphology with average sizes 7-10 $\mu \mathrm{m}$. 
The difference in morphological behavior of the two complex systems comprising caseins with a

721

722

723

724

725

726

727

728

729

730

731

732

733

734

735

736

737

738

739

740

741

742

743

744

745

different dispersion state can be explained by taking into account that morphological changes are driven by two types of forces acting in opposite directions; hydrophobic forces leading to aggregation, and weak polarization effects induced by electrostatic forces resulting in dissociation of aggregates. It is well known that MC particles are characterized by a much stronger hydrophobicity than SC molecules. Therefore their complexation with lys (which diminishes electrostatic repulsion) leads to strong association. In the case of the less hydrophobic SC its complexation with lys at a low ChR first leads to association of the complex particles by hydrophobic forces. Starting from a definite length (at a higher ChR), hydrophobic forces acting along the rod-like particles are weakened, and an appearance of new branch points takes place, possibly localized where the SC molecules have a polar amino acid residue, and so on. For ChR values closer to 1, hydrophobic forces start to prevail on the electrostatic ones leading to formation of large complex aggregates.

\section{Conclusion}

The interaction and complexation behavior of lysozyme with two acid SC and MC proteins, the structure and composition of the complex particles, the allocation of the proteins within the complexes, as well as the solution properties and peculiarities of the morphological changes of the complex systems were studied by means of dynamic and static light scattering, fluorescence anisotropy, confocal laser scanning and bright-field light microscopy, phase analysis, electrophoretic mobility, and turbidimetry measurements. The results show that the specific q values for the Lys/MC systems where respectively complex formation ( $\mathrm{q}_{\text {Onset }}$ ) and phase separation $\left(\mathrm{q}_{\phi}\right)$ is initiated were $\sim 33$ times less than those for Lys/SC systems. Determination of the binding constant $(\mathrm{K})$ at $\mathrm{pH} 7.0$ and $I=0.01$ showed only small differences in these values for lys $/ \mathrm{SC}\left(\mathrm{K}=3.3 \times 10^{3} \mu \mathrm{M}^{-1}\right)$ and lys/MC $\left(\mathrm{K}=2.4 \times 10^{3} \mu \mathrm{M}^{-1}\right)$ systems. The solution behavior, structure, effective charge of the formed complexes and protein structure within the complexes proved to be dependent on the state of dispersion of the casein molecules, the $\mathrm{pH}$, and the $\left[\mathrm{Cat}^{+}\right] /\left[\mathrm{An}^{-}\right]$charge ratio $(\mathrm{ChR})$. Absorption measurements indicate complexation of Lys with caseins at $\mathrm{pH}$ values as high as $11.29(I=0.01)$. At 
ChR>1, i.e. in excess of lysozyme, CLSM clearly showed the formation of complex Lys/SC particles

747 with a neutral core and an exterior part consisting exclusively of macromolecules of hydrophilic Lys,

748 which is in agreement with Khokhlov's theory, whereas in the case of Lys/MC particles, the formation

749 of an exterior part was not observed even at $\mathrm{ChR} \geq 4.5$. The conclusions drawn from CLSM were

750 confirmed by the phase analysis of the complex systems at different $\mathrm{ChR}$.

751 The secondary structure of the proteins within the complexes was evaluated by fluorescence 752 spectroscopy and CD measurements. Binding of Lys with SC and MC leads to a disruption of the 753 ordered secondary structure of Lys, mainly in the lysozyme/MC system. Considering the 754 morphological changes of the complex systems as a function of ChR we established that the Lys/SC 755 complex at low ChR (0.1-0.2) consists of small spherical particles which aggregate at higher ChR 756 values forming large vermiform asymmetric particles which eventually reduce to spherical ones at 757 ChR $>8$. The Lys/MC system at low ChR forms weakly asymmetric particles but contrary to the 758 Lys/SC system these particles associate at $\mathrm{ChR} \geq 0.6$ forming a droplet like morphology with average 759 sizes of 7-10 $\mu \mathrm{m}$. Hydrophobic forces acting between particles and weak polarization forces can be a 760 driving force for such morphological changes.

761 The present study provides a better understanding of the interaction and complexation processes of 762 lysozyme with caseins. An understanding of the effect of protein structure on protein-protein 763 interactions also permits the manipulation of protein side chains in order to enhance gelation 764 properties. 
Y.A. Antonov is grateful to KU Leuven for financial support from the Soft Matter Rheology and

768 Technology group. We are thankful to Prof. Dr. Mark Van der Auweraer (Molecular Imaging and 769 Photonics, KU Leuven) for providing access to the fluorescence spectroscopy and fluorescence 770 anisotropy instrumentation. R. Cardinaels is indebted to the Research Foundation-Flanders (FWO) 771 for a postdoctoral fellowship at KU Leuven.

\section{References}

Anema, S. G. \& de Kruif, C. G. K.(2013). Coacervates of lactoferrin and caseins. J Colloid Interface Sci., 398, 255-261.

Antipova, A. S., Semenova, M. G., \& Belyakova, L. E. (1999). Colloids and Surfaces B: Biointerfaces, 12, 261-270.

Antonov, Y. A., \& Moldenaers, P. (2009). Inducing demixing of semidilute and highly compatible biopolymer mixtures in the presence of a strong polyelectrolyte. Biomacromolecules, 10, 3235-3245.

Antonov, Y. A., Zhuravleva, I. L., Cardinaels, R.,\& Moldenaers, P. (2015). Macromolecular complexes of lysozyme with dextran sulfate. Food Hydrocolloids, 44, 71-80.

Aune, K.C., \& Tanford C.(1969). Thermodynamics of the denaturation of lysozyme by guanidine hydrochloride. I. Depdendence on pH at 25 degrees. Biochemistry. 8(11), 45794585 .

Bond, J.P.,\& Notides, A.C.(1988). A chemical kinetic model for ligand binding to identical and independent binding sites in vivo. Anal.Biochem., 238-251.

Bouhallab, S., Croguenneg, T. (2014). Spontaneous assembly and induced aggregation of food proteins. Adv.Polym.Sci., 256, 67-102.

Bourriot, S., Garnier, C., \& Doublier, J.-L. (1999). Phase separation, rheology, and microstructure of micellar casein-guar gum mixtures. Food Hydrocolloids, 13, 43-49.

Carlsson, F., Lines, P., \& Malmsten, M. (2001). Monte Carlo simulations of polyelectrolyteprotein complexation. J. Phys. Chem. B, 105, 9040-9049.

Coers, J., Permyakov, S. E., Permyakov, E. A., Uversky, V. N., Fink, A. L., \& Permyakov,S.E. (2002). Conformational prerequisites for $\alpha$-lactalbumin fibrillation. 
Biochemistry, 41, 12546-12551.

Dalgleish, D. G., Spagnuolo, P. A., \& Goff, H. D. (2004). A possible structure of the casein micelle based on high-resolution field-emission scanning electron microscopy. Int. Dairy $J_{.2}$ 14,1025-1031.

Desfougères, Y., Croguennec, T., Lechevalier, V., Bouhallab, S., \& Nau, F. (2010). Charge and Size Drive Spontaneous Self-Assembly of Oppositely Charged Globular Proteins into Microspheres. J Phys. Chem. B, II4, 4138-4144.

Farrell, H. M. Jr., Qi, P. X., Wickham, E. D., \& Unruh J. J. (2002). Secondary structural studies of bovine caseins: structure and temperature dependence of beta-casein phosphopeptide (1-25) as analyzed by circular dichroism, FTIR spectroscopy, and analytical ultracentrifugation J. Protein Chem. 2002, 21, 307-21.

Greenfield, N.J. (2007). Using circular dichroism spectra to estimate protein secondary structure. Nature Protocols 1, 2876-2890.

Gunton, J. D., Shiryayev, A.,\& Pagan, D. L. (2007). Protein condensation: kinetic pathways to crystallization and disease. Cambridge: Cambridge University Press.

Gurov, A.(1982). Metastable and equilibrium complexes of proteins with dextran sulphate. PhD thesis. Moscow institute of organo-element compounds RAS.

Hipp, N. J., Groves, M. L., McMeekin, T. L. (1952). Acid-Base Titration, Viscosity and Density of $\alpha$-, $\beta$ - and $\gamma$-Casein. J. Am. Chem. Soc., 74 (19), 4822-4826.

Holt, C., Carver, J. A., Ecroyd, H. W. and Thorn, D. C. (2013). Invited review: Caseins and the casein micelle: Their biological functions, structures, and behavior in foods. Journal of Dairy Science, 96 (10), 6127-6146.

functions, structures, and behavior in foods. Journal of Dairy Science, 96 (10), 6127-6146 functions, structures, and behavior in foods. Journal of Dairy Science, 96 (10), 6127-6146.

Howel, N.K. (1992) Protein-protein Interactions. In B.J.F. Hudson, (Ed.), Biochemistry of Food Proteins. (pp. 35-74). Essex: Elsevier Applied Science Publ. Ltd.

Howell, N. J., Sabila, Y., Grootveld, M., \& Williams, S. (1996). High-resolution NMR and magnetic resonance imaging (MRI) studies on fresh and frozen cod J. Sci. Food Agric., 72, 49-56.

Hui. Y.H. (Ed) (2005). Hand Book of Food Science, Technology and Engineering, 1 Volume Set., CRC. Taylor and Francis Group.

Imoto, T., Forster, L. S., Repley, J. A., \& Tanaka. F. (1971). Fluorescence of Lysozyme:Emissions from Tryptophan Residues 62 and 108 and Energy Migration 
Proc. Nat.Acad. Sci. USA, 69, 1151-1155.

Jewell, C. M., Fuchs, S. M., Flessner, R. M., Raines, R. T., \& Lynn, M. (2007). Multilayered films fabricated from an oligoarginine-conjugated protein promote efficient surfacemediated protein transduction. Biomacromolecules, 8, 857-863.

Junhwan, J.; Dobrynin, A. (2005). Molecular dynamics simulations of polyampholyte -polyelectrolyte complexes in solutions. Macromolecules, 38, 5300-5312.

Karayianni, M., Pispas, S., Chryssikos, G. D., \& Gionis, V. (2011). Complexation of Lysozyme with Poly-(sodium(sulfamate-carboxylate)isoprene). Biomacromolecules, 12 , 1697-1706.

Krebs, M. R. H., Wilkins, D. K., Chung, E.W., Pitkeathly, M. C, Chamberlain, A. K., Zurdo, J., Robinson, C.V., \& Dobson, C. M. (2000). Formation and seeding of amyloid fibrils from wild type hen lysozyme and a peptide fragment from the $\beta$-domain. J.Mol. Biol., 300, 541549.

Krebs, M.R.H., Delvin,G.L., \& Donald, A.M. (2007). Protein particulates: another generic form of protein aggregation? Biophys.J., 92, 1336-1342.

Van der Linden, E., \& Venema, P. (2007). Self-assembly and aggregation of proteins. Curr. Opin. Colloid Interface Sci.,12, 158-165.

Kuehner, D. E., Engmann, J., Fergg, F., Wernick, M., Blanch, H. W., \& Prausnitz, M. (1999). Lysozyme Net Charge and Ion Binding in Concentrated Aqueous Electrolyte Solutions" J. Phys. Chem. B, 103, 1368-1374.

Kuramitsu, S., Kurihara, S., Ikeda, K., \& Hamaguchi, K. (1978). Fluorescence spectra of hen, turkey, and human lysozymes excited at 305 nm. J. Biochem., 83, 159-170.

Lakowicz, J. R. (1986). Principles offluorescence spectroscopy., New York and London: Plenum Press.

Lakowicz, J. R. (2006). Principles of Fluorescence Spectroscopy, $\left(3^{\text {rd }} \mathrm{ed}\right)$. New York: Springer.

Lin, X., Zhao, W., Wang, X. (2010). Characterization of conformational changes and noncovalent complexes of myoglobin by electrospray ionization mass spectrometry, circular dichroism and fluorescence spectroscopy. J. Mass Spectrom. 45, (6), 618-626.

Liu, S. H., Cao, Y. L., Ghosh, S., Rousseau, D., Low, N. H., \& Nickerson, M. T. (2010). Intermolecular Interactions during Complex Coacervation of Pea Protein Isolate and Gum Arabic J. Agric. Food Chem., 58, 552-556. 
Luo, Y. Z., \& Baldwin, R. L.(1999). Interaction between water and polar groups of the helix backbone: An important determinant of helix propensities. Proc. Natl. Acad. Sci. USA, 96, 4930-4935.

Marchin, S., Putaux, J.-L., Pignon, F., \& Léonil, J. (2007). Effects of the environmental factors on the casein micelle structure studied by cryo transmission electron microscopy and smallangle X-ray scattering/ultrasmall-angle X-ray scattering.J. Chem. Phys., 126, 045101, 1-10.

Mattison, K.W., Brittain, I. J., \& Dubin, P. L.(1995). Protein-Polyelectrolyte Phase Boundaries. Biotechnology progress, 11, 632-637.

McMahon, D. J.\& Oommen, B. S.(2013). Casein micelle structure functions and interactions In: L. H. Paul McSweeney, \& Patrick F. Fox (Eds), Advanced Dairy Chemistry, Ch 6,(pp 185-209). New York: Springer science+Business media.

Michaels, A. S., Mir, L., \& Schneider, N. S. (1965). A conductometric study of polyaction-polyanion reactions in dilute solution. J. Phys. Chem., 69, 1447-1455.

Michaels, A. S., Falkenstein, G. L.,\& Schneider, N. S.(1965). Dielectric properties of polyanion-polycation Ccmplexes J. Phys. Chem., 69, 1456-1465.

Nishimoto, E., Yamashita, S., Szabo, A. G., Imoto, T. (1998). Internal motion of lysozyme studied by time resolved fluorescence depolarization of tryptophan residues. Biochemistry, 37, 5599-5607.

Panouillé, M., Nicolai, T.,\& Durand, D. (2004). Heat induced aggregation and gelation of casein submicelles Int. Dairy J., 14, 297-303.

Park, J.M, Muhoberac, B. B., Dubin, P.L., \& Xia, J. (1992). Effects of protein charge heterogeneity in protein-polyelectrolyte complexation J. Macromolecules, 25, 290-295.

Park, W.,\& Na, K. (2009). Polyelectrolyte complex of chondroitin sulfate and peptide with lower $\mathrm{pI}$ value in poly(lactide-co-glycolide) microsphere for stability and controlled release.Colloids Surf., 72, 193-200.

Parmar, A. S., \& Muschol, M.(2009). Hydration and hydrodynamic interactions of lysozyme: Effects of chaotropic versus kosmotropic ions. Biophys. J., 97, 590-598.

Pitkowski, A., Durand, D., \& Nicolai T. (2008). Structure and dynamical mechanical properties of suspensions of sodium caseinate. J Colloid Interface Sci., 326, 96-102.

Polyakov, V. I., Grinberg, V. Y., Antonov, Y .A., \& Tolstoguzov, V. B. (1979). Limited thermodynamic compatibility of proteins in aqueous solutions. Polym.Bull., 1, 593-597.

Rezwan, K., Meier, L. P., \& Gauckler, L. (2005). Lysozyme and bovine serum albumin adsorption on uncoated silica and $\mathrm{AlOOH}$-coated silica particles: the influence of positively and negatively charged oxide surface coatings. J. Biomaterials, 26, 43514357. 
Sarmento, B., Ribeiro, A., Veiga, F., Sampaio, P., Neufeld, R., \& Ferreira, D. (2007). Alginate/chitosan nanoparticles are effective for oral insulin delivery. Pharm. Res., 24, 2198-2206.

Sato, H., \& Nakajima, A. (1974). Complex coacervation in sulfated polyvinyl alcohol aminoacetalyzed polyvinyl alcohol system. Colloid and Polym. Sci., 252, 294-297.

Sato, H., Maeda, M., \& Nakajima, A. (1979). Mechanochemistry and permeability of polyelectrolyte complex membranes composed of poly (vinyl alcohol) derivatives. J. Appl. Polym. Sci., 23, 1759-1767.

Sato, T., Mattison, K. W., Dubin, P. L., Kamachi, M., and Morishima, Y. (1998). Effect of Protein Aggregation on the Binding of Lysozyme to Pyrene-labeled Polyanions. Langmuir, $14,5430-5437$.

Schmidt, S., Havekost, D., Kaiser, K., Kauling, J., \& Henzler. H. (2005). J. Engineering in Life Sciences, 5, 273-276.

Schuck, P., Piot, M., Mejean, S., Legraet, Y., Fauquant, J., Brule, G., \& Maubois, J.-L.(1994). Deshydratation par atomisation dephosphocaseinate natif obtenu par microfiltration sur membrane. Lait, 74, 375-388.

She, Z., Antipina, M. N., Li, J., Sukhorukov, G. B. (2010). Mechanism of protein release from polyelectrolyte multilayer microcapsules. Biomacromolecules, 11, 1241-1247.

Sophianopoulos, A. J.; Vanholde, K. J. (1961) Evidence for dimerization of lysozyme in alkalin solution. Biol. Chem., 236, PC82-PC83.

Sophianopoulos, A. J., \& Vanholde, K. (1964). Physical studies of miramidase (lysozyme) II: pH dependent dimerization. J. Biol. Chem., 239, 2516-2524.

Storey, B. T., Lee, C. P., Papa, S., Rosen, S. G., \& Simon, G. (1976). Light scattering from suspensions of membrane fragments derived from sonication of beef heart mitochondria Biochem., 15, (4), 928-933.

Swaisgood, H.E. (1992). Chemistry of the caseins. In: P.F. Fox (Ed.) Advanced Dairy Chemistry-I: Proteins. (pp. 63-110.) New York, NY: Elsevier Applied Science.

Takahashi, D., Kubota, Y., Kokai, K., Izumi, T., Hirata, M., \& Kokufuta, E. (2000). Effects of surface charge distribution of proteins in their complexation with polyelectrolytes in an aqueous salt-free system. Langmuir, 16, 3133-3140.

Thompson, A. R. (1955). Amino acid sequence in lysozyme. 2. Elution chromatography of peptides on ion-exchange resins. Biochem. J., 60, 507-515.

Tsuboi, A., Izumi, T., Hirata, M., Xia, J., Dubin, P. L., \& Kokufuta, E. (1996). Complexation of proteins with a strong polyanion in an aqueous salt-free System. Langmuir 12, 6295- 
6303.

Tuinier, R., De Kruif, C. G. (2002). Stability of casein micelles in milk. J. Chem. Phys., 117, $1290-1295$

Valstar, A., Brown, W., \& Almgren, M. (1999). Interactions of globular proteins with surfactants studied with fluorescence probe methods Langmuir, 15, 2635-2643.

Vasilevskaya, V.V., Leclercq, L, Boustta, M., Vert, M., \& Khokhlov, A.R. (2007). Macromolecules, 40, 5934-5940.

Weiping, W., Wenao, M., Jianrong, C., Xiaohua, W., \& Zhide, H. (2011). Binding study of diprophylline with lysozyme by spectroscopic methods. J. Luminescence, 131, 820-824.

Winkler,R.G., Roland,G., \& Cherstvy, A.G. (2014). Strong and weak polyelectrolyte adsorption onto oppositely charged curved surfaces In M. Muller, (Ed), Polyelectrolyte complexes in the dispersed and solid state.I. Principles and theory (pp.1-56).New York: Springer.

Woody, R. W. (1995). Circular dichroism. Methods Enzymol., 246, 34-71.

Unneberg P., Merelo, J. J., Chacón, P., \& Morán, F. (2001). SOMCD: method for evaluating protein secondary structure from UV circular dichroism spectra. Proteins, 42, 460-470.

Uversky, V., \& Fink, A. L. (2006). Protein misfolding, aggregation, and conformational Disease. Part A: Protein aggregation and conformational diseases. Singapore: Springer Science+ Business Media, Inc.

774

\section{Captions for Tables and Figures}

Table 1. Results of fitting binding isotherms with a binding model based on independent identical binding sites.

Figure 1. The turbidity values at $500 \mathrm{~nm}\left(\tau_{500}\right)$ as a function of both the weight ratio $\mathrm{q}$ (bottom axis) and charge ratio $\mathrm{ChR}$ (top axis) for lys/SC (a, a', a", b, b') and lys/MC (c, c', c", d, d') mixtures at $I=0.01, \mathrm{pH} 7$ and $23^{\circ} \mathrm{C}$. In (a, a', a", c, c', c") - the concentration of caseins in the complex system $\left(\mathrm{C}^{\mathrm{M}}{ }_{\mathrm{SC}}, \mathrm{C}^{\mathrm{M}}{ }_{\mathrm{MC}}\right)$ is variable. In $\left(\mathrm{b}, \mathrm{b}^{\prime}, \mathrm{d}, \mathrm{d}^{\prime}\right)$ the concentration of caseins in the complex system $\left(\mathrm{C}^{\mathrm{M}}{ }_{\mathrm{SC}}, \mathrm{C}^{\mathrm{M}}{ }_{\mathrm{MC}}\right)$ is constant $(0.01 \mathrm{wt} \%)$. In the insets (a', a', b', c', c', d', d") qonset and $\mathrm{q}_{\text {set }}$ indicate the transitions between no complex formation and formation of soluble complexes whereas $\mathrm{q}_{\phi}$ and $\mathrm{q}_{\phi}^{*}$ indicate the transitions between formation of soluble and insoluble complexes. 
Figure 2 (a) The zeta potential ( $\xi$ ) as a function of the weight ratio q for ternary lys/SC (circle) and

787

788

789

790

791

792

793

794

795

796

797

798

799

800• Figure 6. Confocal microscopy images of lys/MC mixtures at different charge ratio ChR values. (a) lys/MC (open star) mixtures. (b) The yield of the complex in the biopolymer rich complex phase (curves 1 and 3) as a function of weight ratio q and the lys/casein weight ratio in the complex phase as a function of weight ratio q (curves 2 and 4) for lys/SC (curves 1 and 2) and lys/MC (curves 3 and 4$)$. $\mathrm{pH} 7.0 ; I=0.01$ and $23^{\circ} \mathrm{C}$.

Figure 3. (a) Binding isotherms of lysozyme to $\mathrm{SC}$ and $\mathrm{MC}$ at $\mathrm{pH} 7.0, I=0.01$ and $23^{\circ} \mathrm{C}(\mathrm{b}, \mathrm{c})$ Fit of independent binding site model for binding ratio $v$ versus free ligand concentration $\mathrm{L}$ for (b) lys/SC and (c) lys/MC mixtures.

Figure 4. (a, b) The intensity size distribution and (c, d) number size distribution for lys/SC (a, c) and lys/MC (b, d) mixtures. The average size of the complex particles for lys/SC (a',c') or lys/MC (b', d') mixtures as a function of charge ratio $\mathrm{ChR} . \mathrm{C}^{\mathrm{M}}$ tot $=0.02 \mathrm{wt} \%, \mathrm{pH} 7.0, I=0.01$ and $23^{\circ} \mathrm{C}$.

Figure 5. Confocal microscopy images of lys/SC mixtures at different charge ratio ChR values. (a) ChR 0.41, (b) ChR 1.0 and (c) ChR 3.9 for $\mathrm{pH} 7.0, I=0.01$ and $23^{\circ} \mathrm{C} . \mathrm{C}^{\mathrm{M}}$ tot $=0.02 \mathrm{wt} \%$. Lys is labeled orange and SC and MC are labeled yellow. Full length of images is $208 \mathrm{um.}$

801 ChR 0.16, (b) ChR 0.44, (c) ChR 1.15, (d) ChR 1.47 (e) ChR 1.64 (f) ChR 4.1 for pH 7.0, I=0.01 802 and $23^{\circ} \mathrm{C} . \mathrm{C}^{\mathrm{M}}$ tot $=0.02 \mathrm{wt} \%$. Lys is labeled orange and SC and MC are labeled yellow. Full length of images is $208 \mathrm{um}$

Figure 7. (a) Radius of gyration $\left(\mathrm{R}_{\mathrm{g}}\right)$ as a function of the charge ratio ChR for lys/SC mixtures, (b) Apparent molecular weight of the complex particles as a function of the charge ratio $\mathrm{ChR}$ for the same system. $\mathrm{C}^{\mathrm{M}}{ }_{\text {tot }}=0.1 \mathrm{wt} \%, \mathrm{pH} 7.0 ; \mathrm{I}=0.01$ and $23^{\circ} \mathrm{C}$.

807 Figure 8. Schematic representation of the complex structure as a function of charge ratio for SC 808 and MC.

809 Figure 9. (a) Representative turbidimetric curve showing the determination of $\mathrm{pH}_{\mathrm{Set}}$ and $\mathrm{pH}_{\phi}$ values for lys/SC mixtures at $I=0.01$. (b) turbidimetric titration curves for lys/SC mixtures determined at 
811 different ionic strengths. (c) $\mathrm{pH}_{\mathrm{Set}}$ of lys/SC mixtures as a function of $I$ value. $\mathrm{C}^{\mathrm{M}}{ }_{\mathrm{SC}}=0.01 \mathrm{wt} \%$.

$812 \mathrm{ChR}=0.985,23^{\circ} \mathrm{C}$.

813 Figure 10. (a) Circular dichroism spectra for a lysozyme solution and lys/SC mixtures with

814 different weight ratios q. All spectra are presented after subtraction of the contribution of SC. (b)

815 Circular dichroism spectra for a $\beta$-casein solution and $\beta$-casein/lys mixtures with different weight

816 ratios q. All spectra are presented after subtraction of the contribution of lys. $\mathrm{C}_{\text {cas }}^{\mathrm{M}}=0.005 \mathrm{wt} \%$, $\mathrm{pH}$

$817 \quad 7.0, I=0.01$ and $23^{\circ} \mathrm{C}$.

818 Figure 11. Circular dichroism spectra for a lys solution and lys/MC mixtures with different weight

819 ratios q. All spectra are presented after subtraction of the contribution of $\mathrm{MC} . \mathrm{C}^{\mathrm{M}} \mathrm{lys}_{\mathrm{s}}=0.005 \mathrm{wt} \%$,

$820 \mathrm{pH} 7.0 ; \mathrm{I}=0.01$ and $23^{\circ} \mathrm{C}$.

821 Figure 12. Fluorescence emission spectra for a lys solution and lys/SC (a) or lys/MC (b) mixtures

822 at different q values. All spectra are presented after subtraction of the contribution of SC or MC.

$823 \mathrm{C}_{\text {lys }}=0.005 \mathrm{wt} \%, \lambda_{\text {exc }}=280 \mathrm{~nm}, \mathrm{pH} 7.0, I=0.01$ and $23^{\circ} \mathrm{C}$. The inset in (a) shows the wavelength at

824 which maximum emission occurs as a function of the weight ratio q.

825 Figure 13. Morphological changes in lys/SC and lys /MC mixtures as a function of charge ratio

$826 \mathrm{ChR} \cdot \mathrm{C}_{\mathrm{SC}}^{\mathrm{M}}=0.02 \mathrm{wt} \%, \mathrm{C}^{\mathrm{M}}{ }_{\mathrm{MC}}=0.02 \mathrm{wt} \%$, concentration of lys in the mixtures $\left(\mathrm{C}_{\text {Lys }}^{\mathrm{M}}\right)$ is variable.

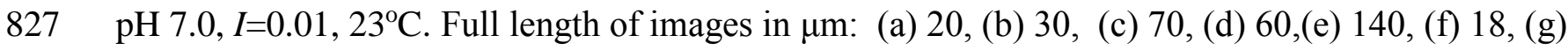

82870, (h) 55, (i) 55, (j) 70, (k) 80, (1) 90.

\section{Highlights (for review)}

1. Structure of the complex particles and distribution of lysozyme within them are strongly dependent on the state of the casein molecules (SC or MC).

2. The solution behavior of the complexes and their morphology as well as the protein structure within the complexes are dependent on the $\left[\mathrm{Cat}^{+}\right] /\left[\mathrm{An}^{-}\right]$charge ratio.

3. In excess of lysozyme, complex Lys/SC particles with a neutral core and an exterior part consisting exclusively of hydrophilic Lys macromolecules are formed.

4. In the case of $\mathrm{Lys} / \mathrm{MC}$ system a uniform distribution of both proteins within the complex particles was observed in a wide range of $\left[\mathrm{Cat}^{+}\right] /\left[\mathrm{An}^{-}\right]$charge ratio. 

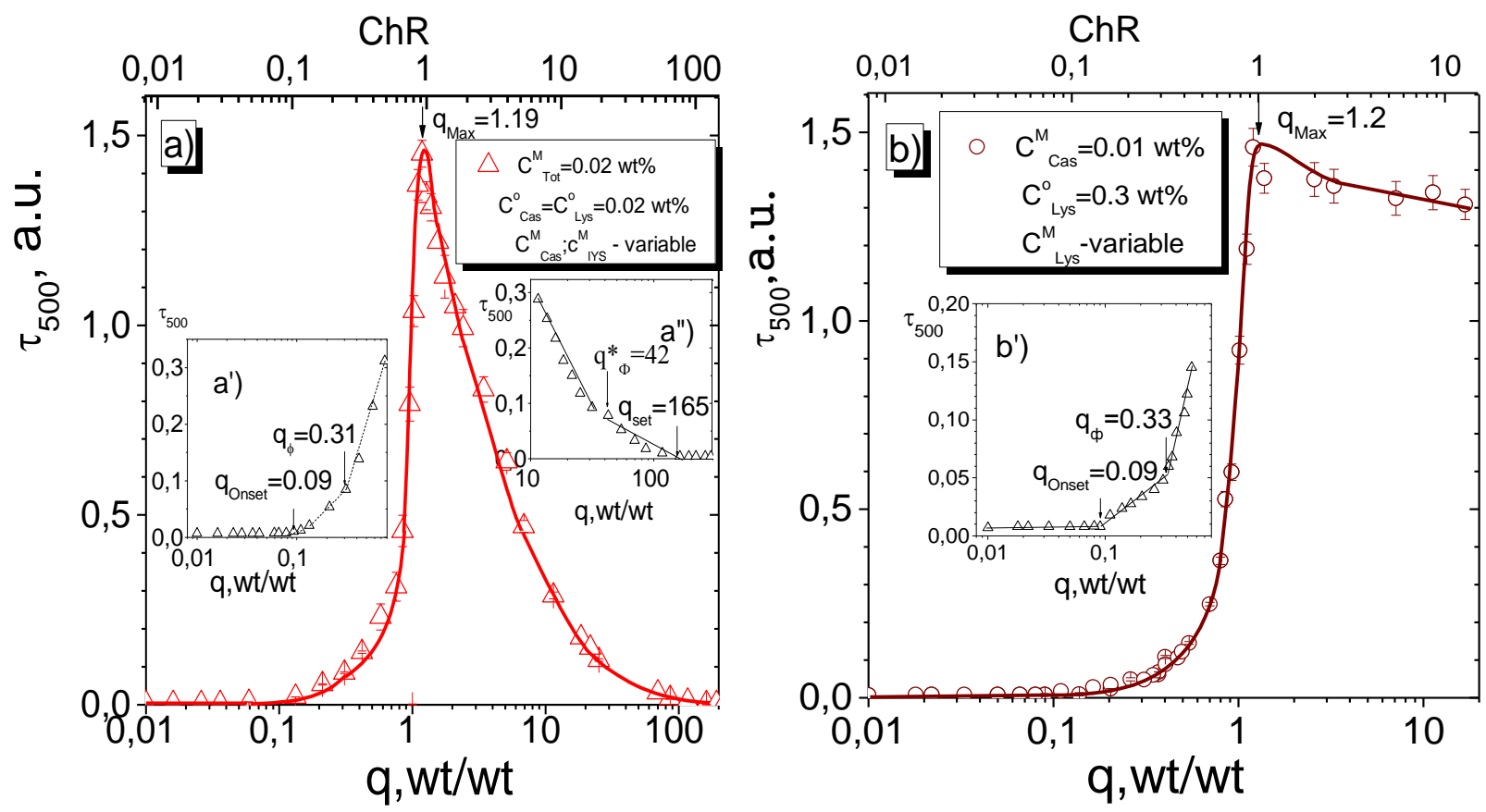

ChR
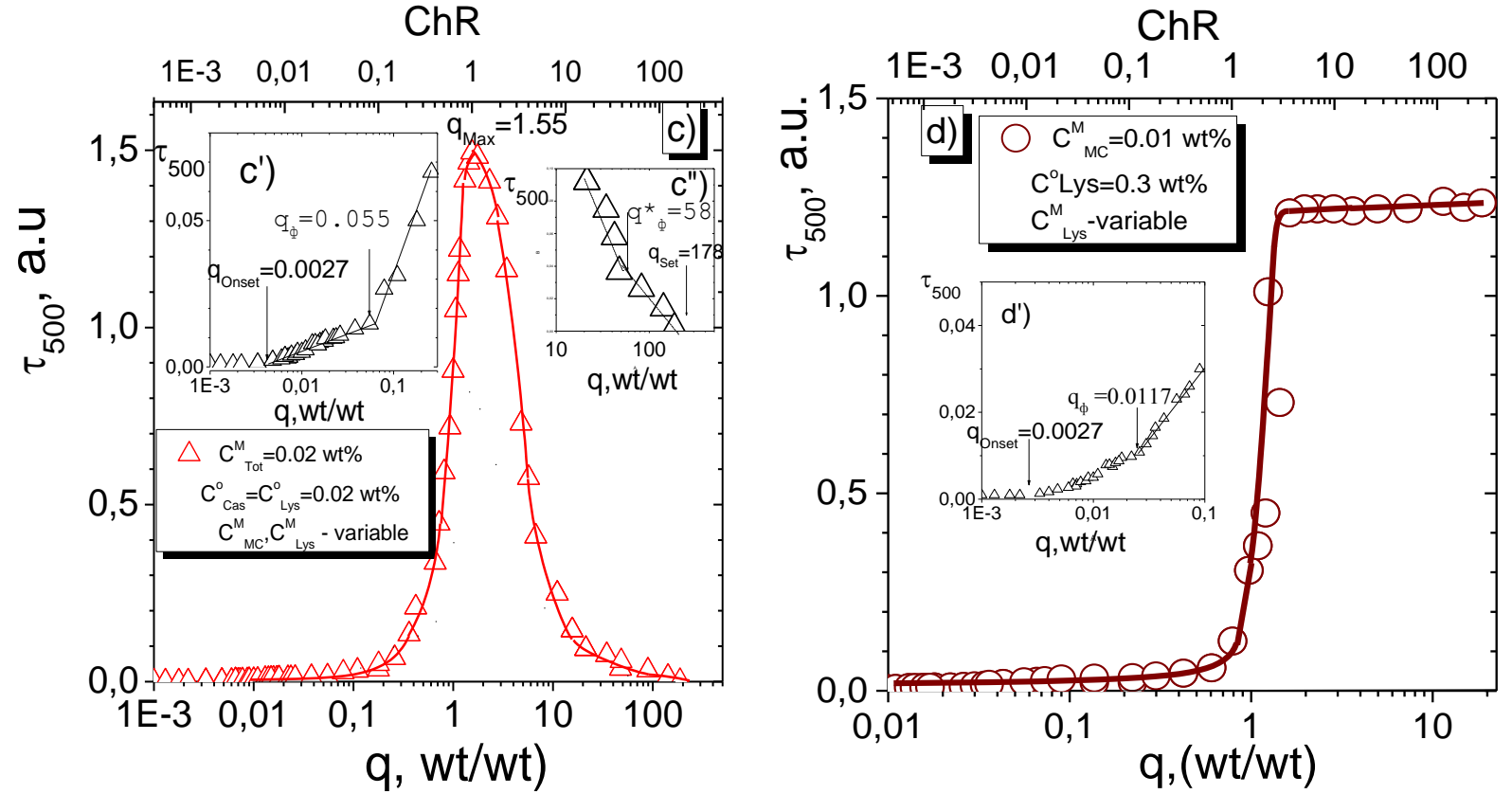

Figure 1. 

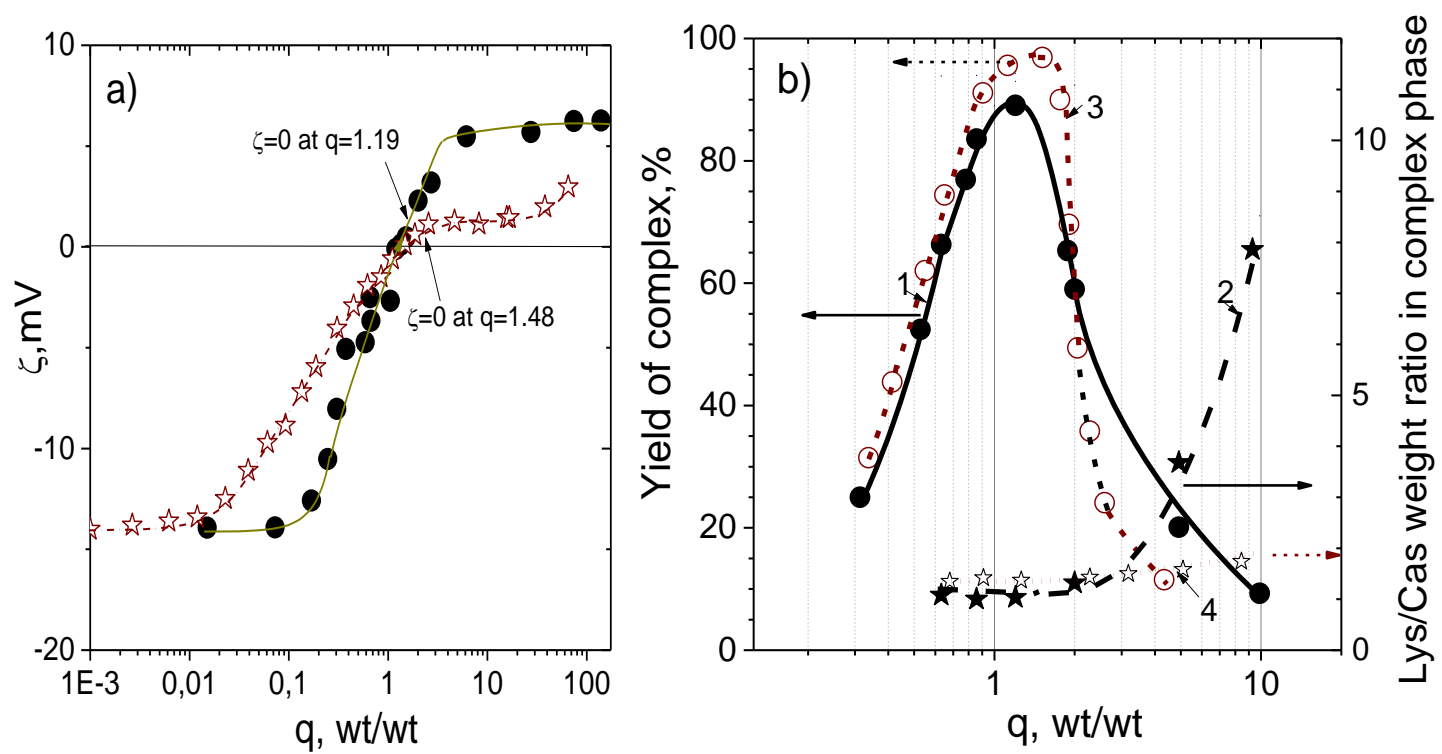

Figure 2 

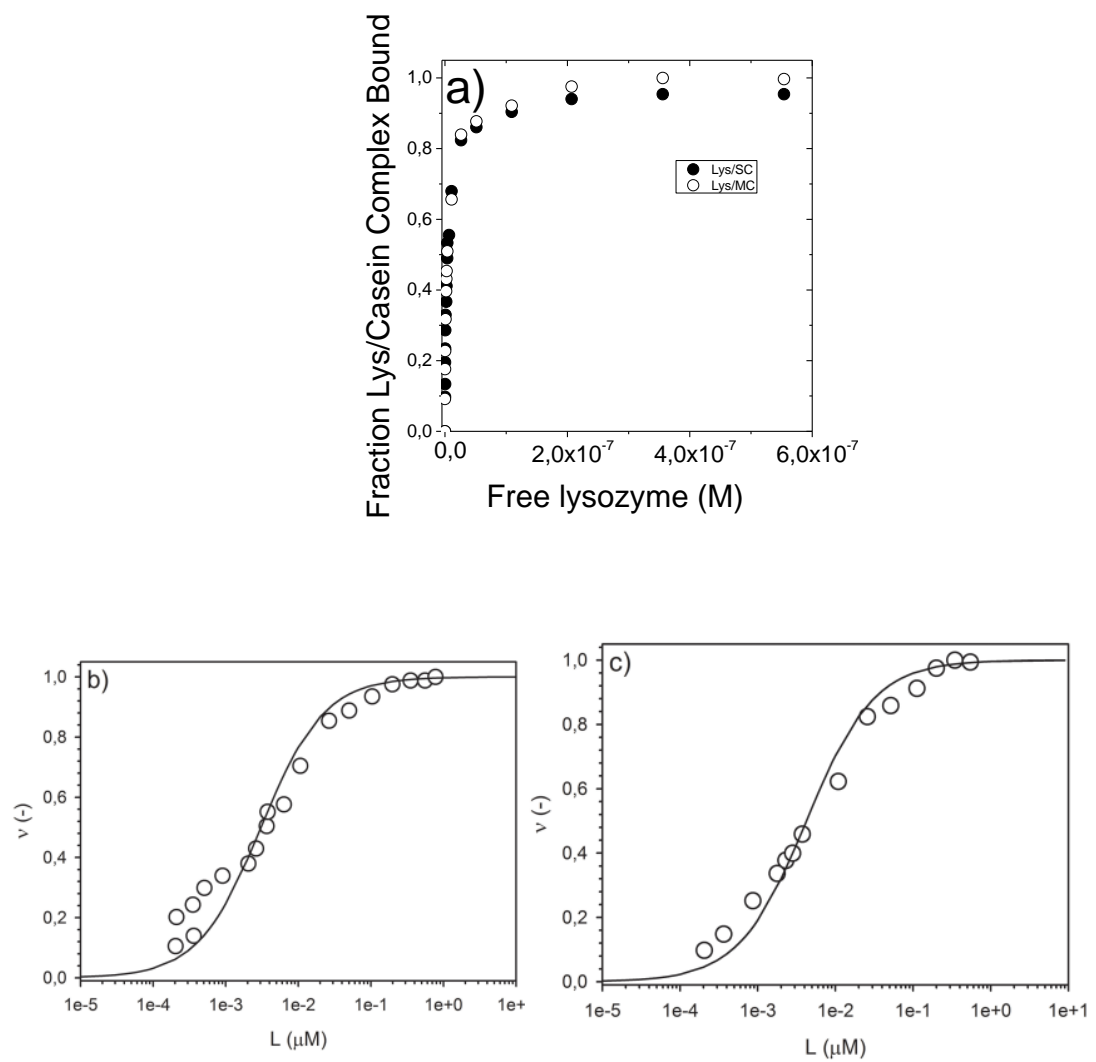

Figure 3 

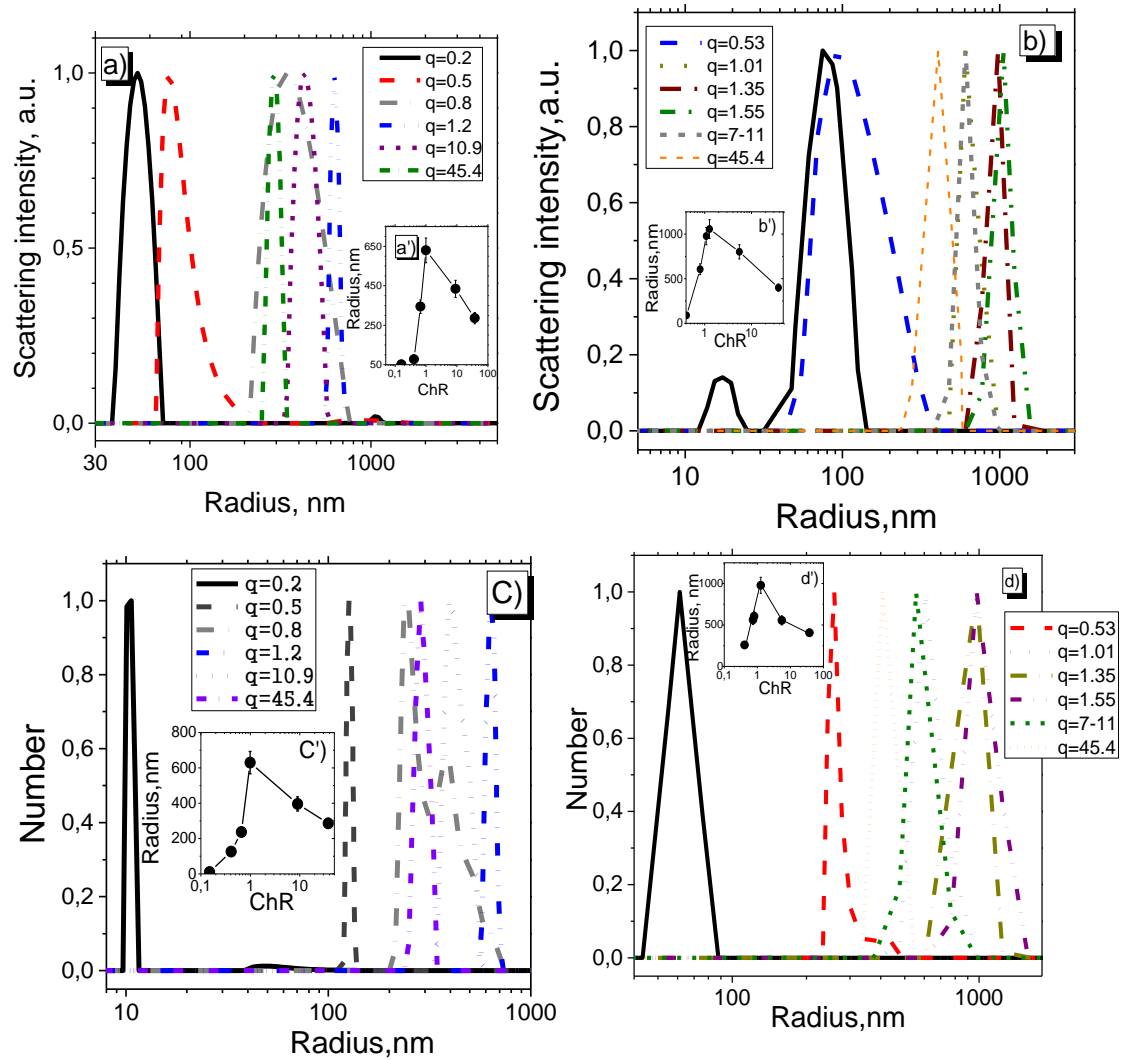

Figure 4 


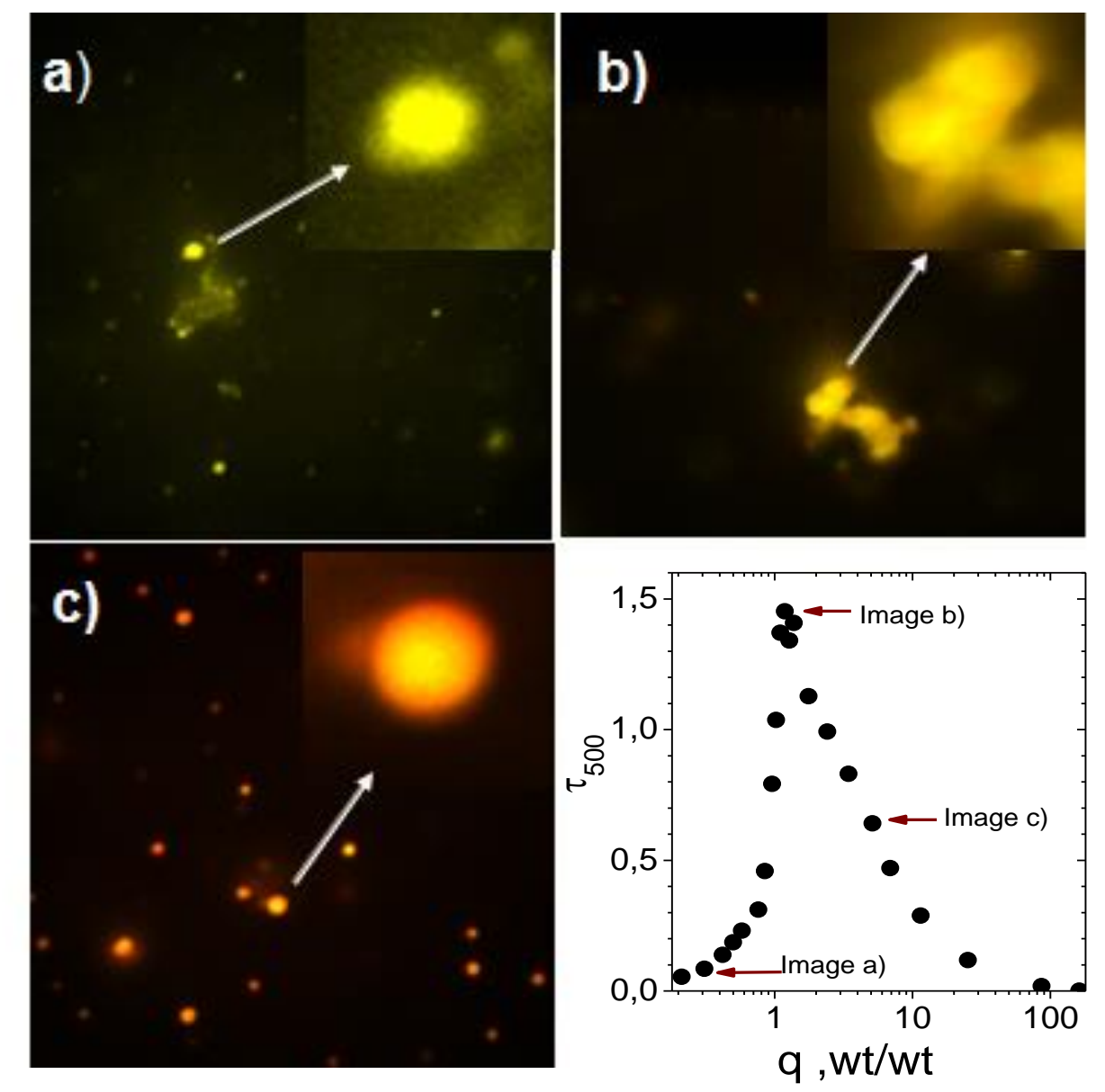

Figure 5 


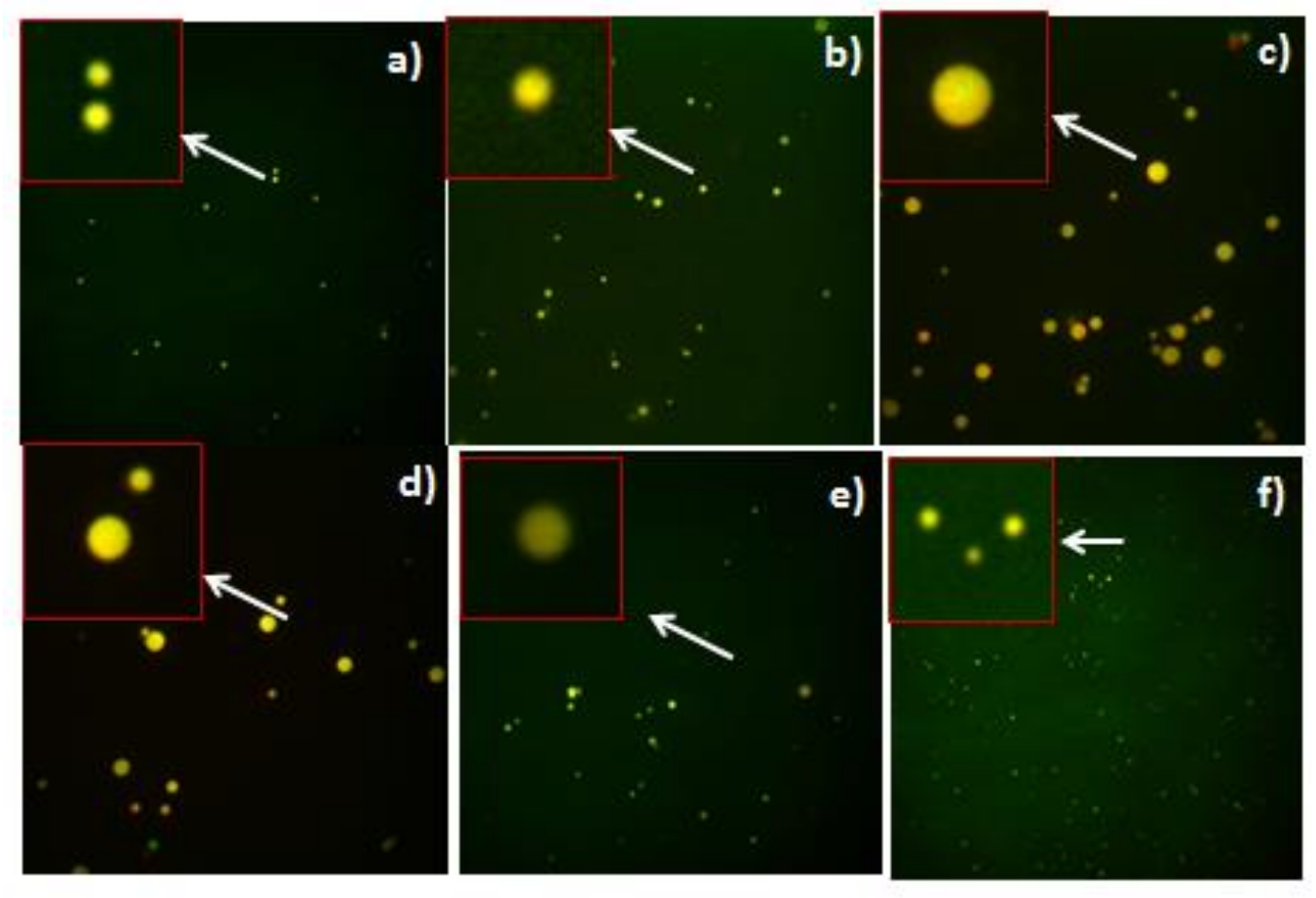

Figure 6 

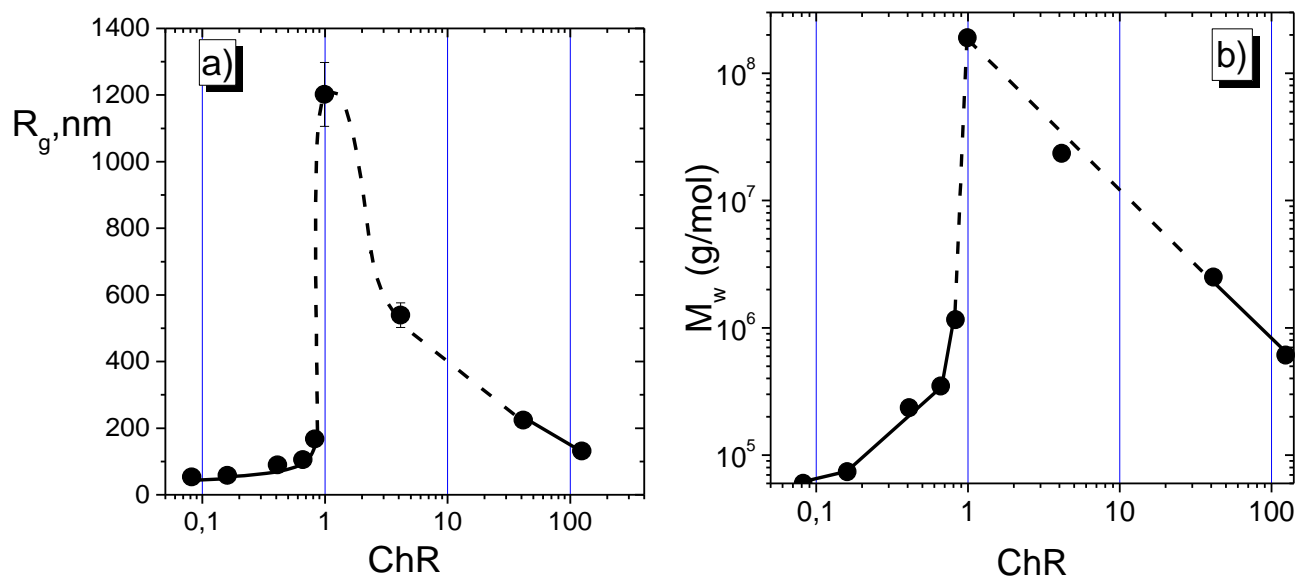

Figure 7 


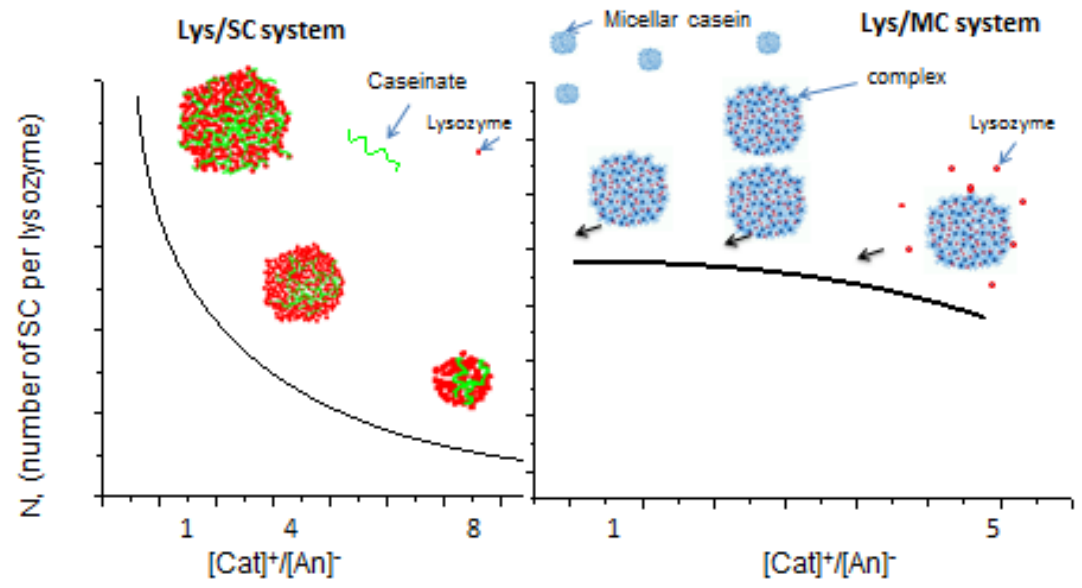

Figure 8 

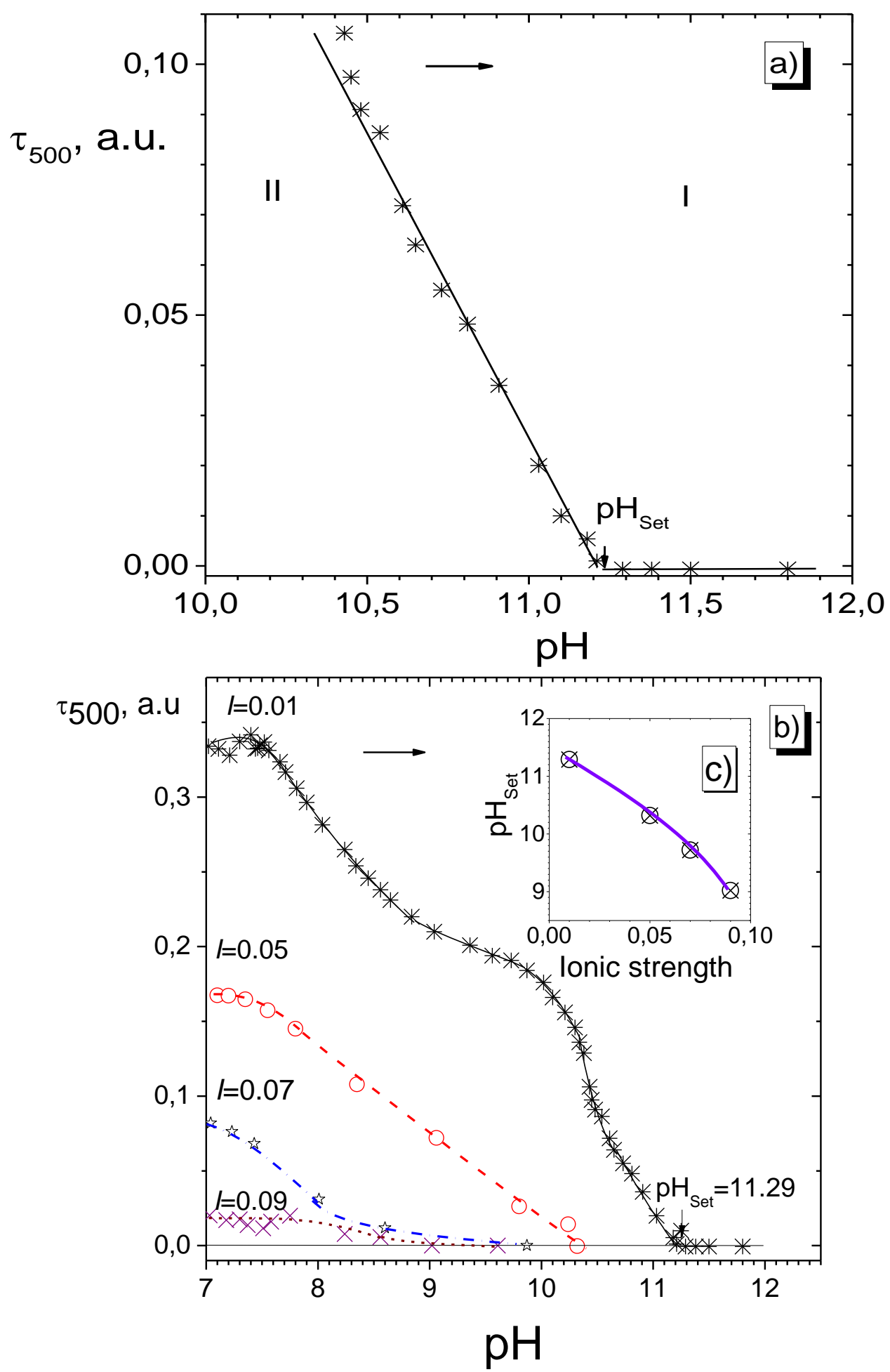

Figure 9 


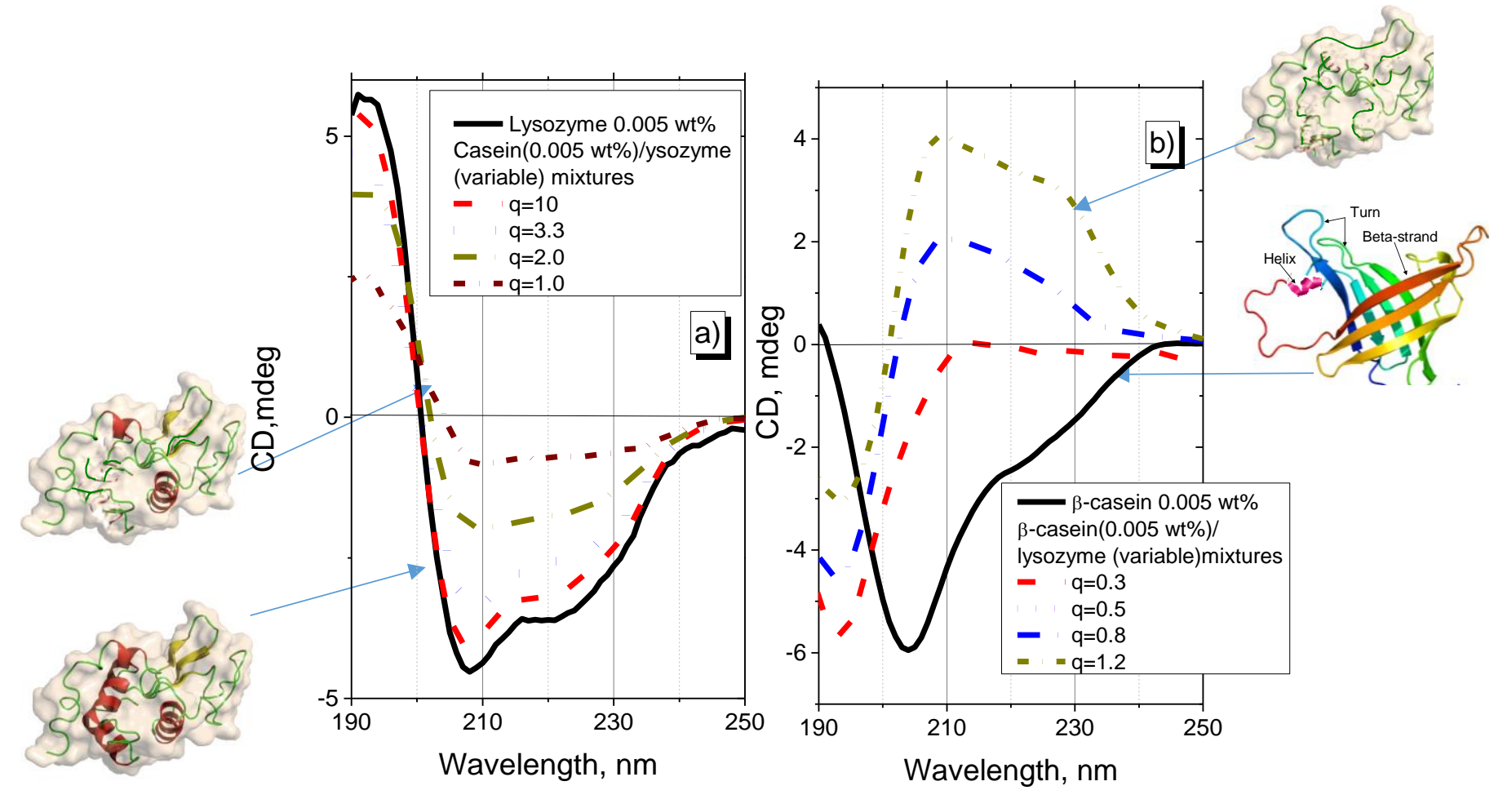

Figure 10 


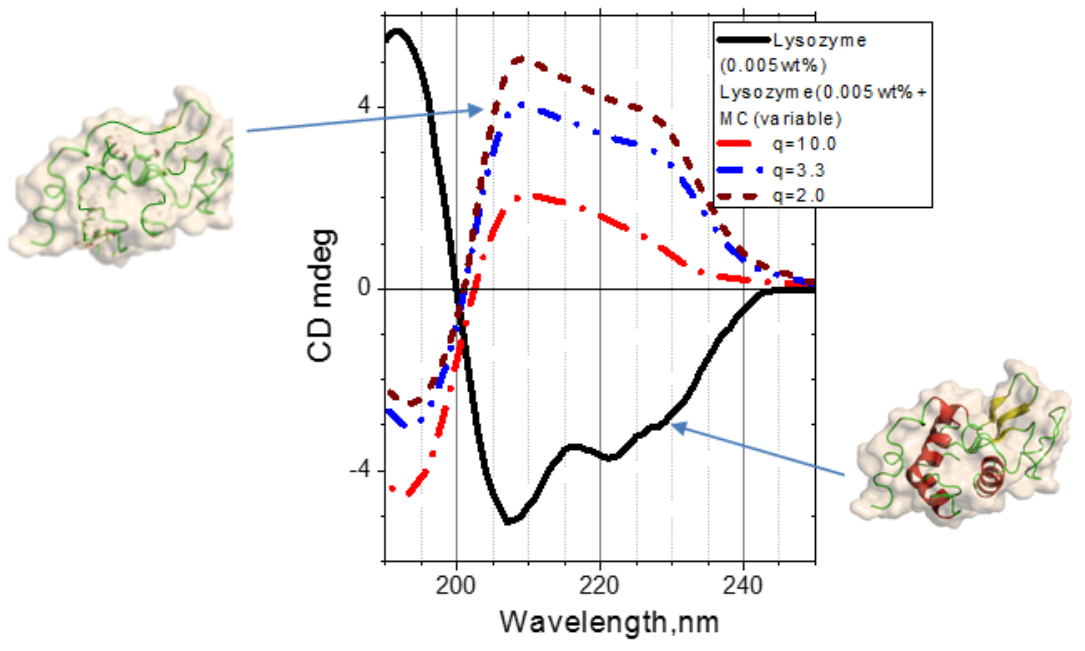

Figure 11. 

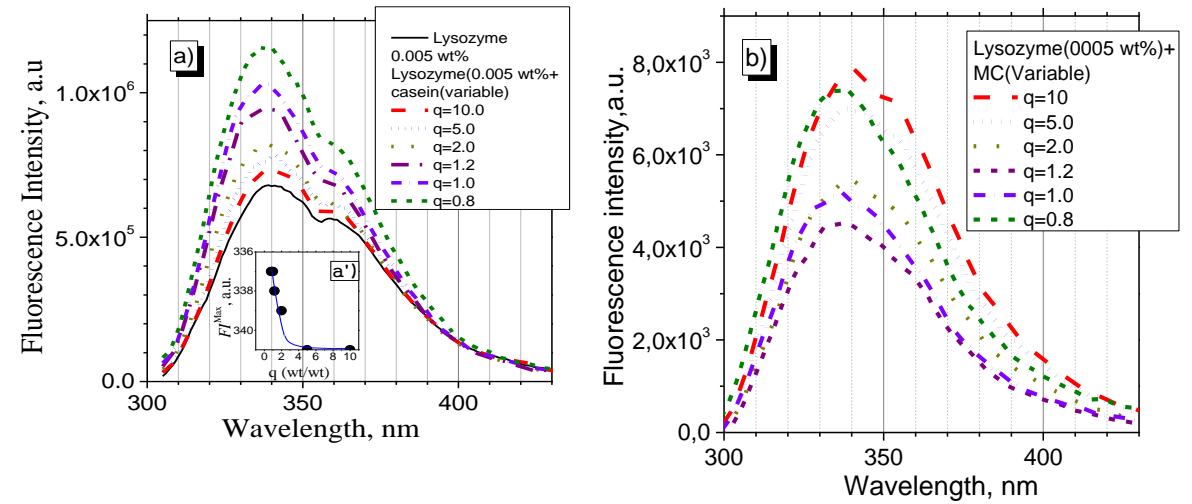

Figure 12. 
Effect of the ChR on Morphology of the Complex Particles

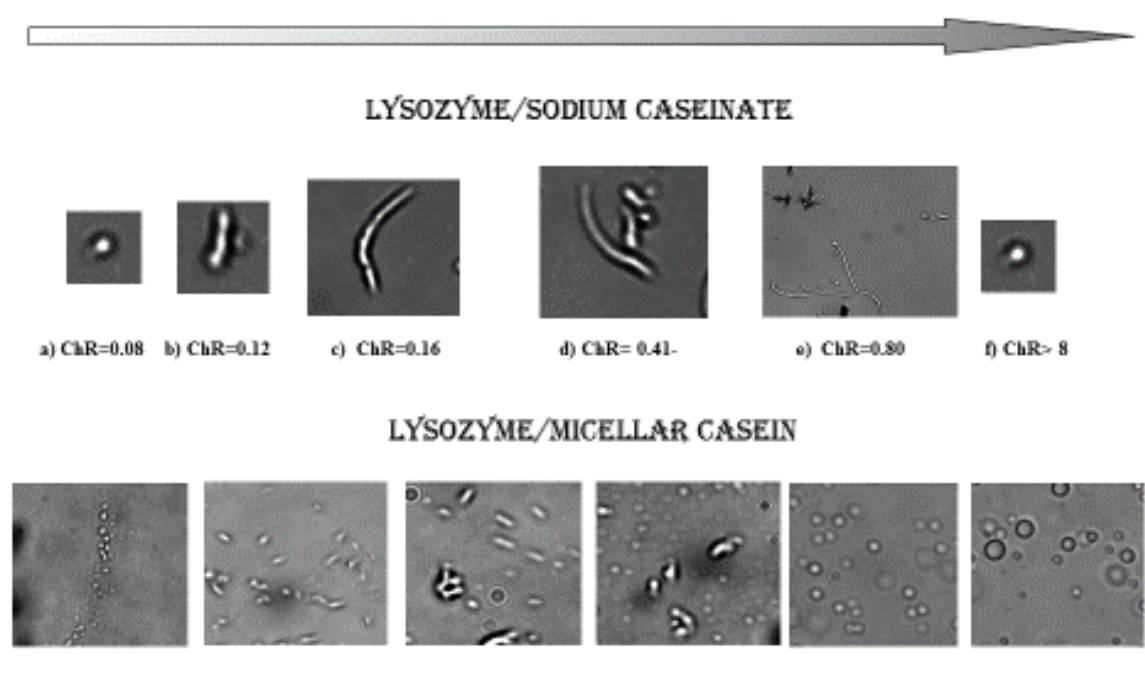

$\begin{array}{llllll}\text { g) } C h R=0.01 & \text { h) } C h R=0.33 & \text { i) } C h R=0.41 & \text { J) } C h R=0.66 & \text { k) } C h R=1.0 & \text { l) } C h R=1.26\end{array}$

Figure 13 
Table 1

\begin{tabular}{|l|l|l|l|}
\hline System & $\begin{array}{l}\text { Binding constant, } \\
\mathrm{K}, \mu \mathrm{M}^{-1}\end{array}$ & $\begin{array}{l}\text { Coefficient of } \\
\text { correlation, } \mathrm{r}\end{array}$ & $\begin{array}{l}\text { Sum of squared } \\
\text { deviations }\end{array}$ \\
\hline Lys/SC & $3.3 \times 10^{2}$ & 0.945 & 0.103 \\
\hline Lys/MC & $2.4 \times 10^{2}$ & 0.976 & 0.034 \\
\hline
\end{tabular}

\section{The TOC graphic}

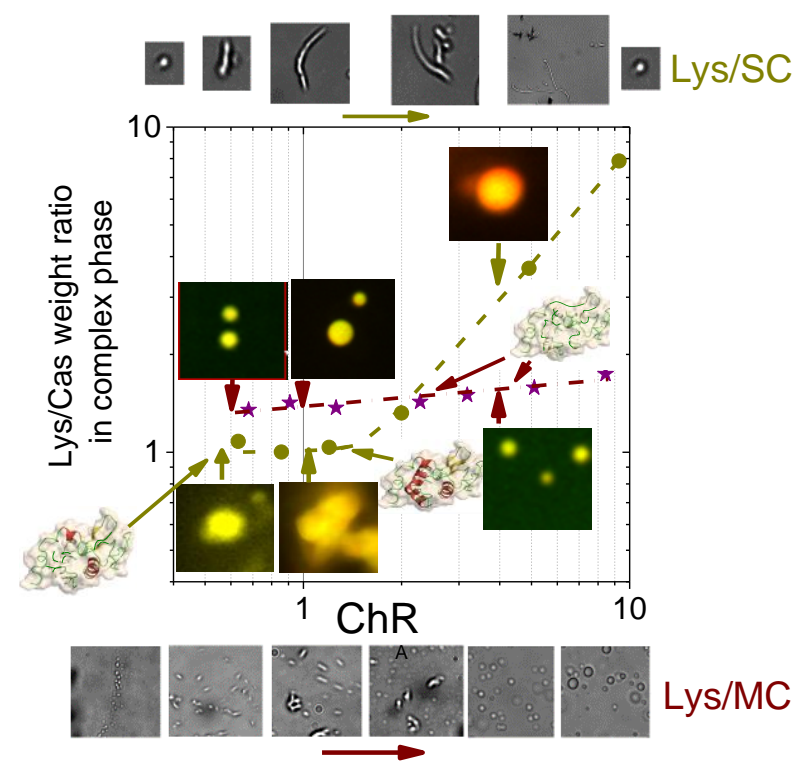

